\title{
Long-Term Changes in Purposive and Reflexive Responses to Nociceptive Stimulation Following Anterolateral Chordotomy
}

\author{
Charles J. Vierck, Jr., Joel D. Greenspan ${ }^{\mathrm{a}}$ and Louis A. Ritz ${ }^{\mathrm{b}}$ \\ Department of Physiology, University of North Carolina School of Medicine, Chapel Hill, North Carolina 27514
}

\begin{abstract}
Macaca nemestrina monkeys received unilateral interruption of the spinothalamic tract, producing contralateral hypalgesia and a bilateral decrease in amplitude of the flexion reflex. These effects on operant escape and reflex responses to electrocutaneous stimulation (ES) were monitored for months to evaluate relationships between the extent of each lesion and the presence or absence of recovery from the early postoperative deficits.

Before surgery, the animals were trained to perform an operant response that terminated ES to the lateral calf of either leg. The durations of ES tolerated by each monkey were inversely related to stimulus intensities within the pain sensitivity range of human subjects. The vigor of operant escape responses and the frequency of intertrial pulls of the manipulandum were directly related to stimulus intensity. Following anterolateral chordotomy at an upper thoracic level, these measures revealed a contralateral hypalgesia for each animal.
\end{abstract}

Operant responsivity to stimulation contralateral to the lesion recovered to control levels for 7 animals (group R). Sustained contralateral recovery of operant reactivity was not observed for 8 monkeys (group U). Most of the lesions in groups $R$ and $U$ were similar in extent and location, involving the classical distribution of the spinothalamic tract (in the anterolateral and ventral columns). Thus, recovery was not determined solely by lesion configuration. However, when recovery did occur, it was associated with medially extensive lesions. A subgroup of 3 unrecovered animals received superficial lesions that did not substantially involve the gray matter or the ventral columns.

For all animals, reflex magnitudes were initially diminished bilaterally and then increased over months of testing. Reflex recovery was greater for the animals that demonstrated recovery of intentional reactions to nociception (group R). An ipsilateral hyperreflexia became apparent for group R. Contralateral recovery to normal levels was observed for group $R$ but not for group $U$. The time course of recovery for operant

\footnotetext{
Received Sept. 20, 1989; revised Jan. 24, 1990; accepted Jan. 31, 1990.

Supported primarily by Program Project Grant NS-14899 from the National Institute of Neurological and Communicative Disorders and Stroke. Additional support was provided from NINCDS grants NS-06347, NS-06835, NS-07261, NS-23683, and NS-07166. The technical assistance of Michael Young and Ruth Rand is gratefully acknowledged.

Correspondence should be addressed to Charles J. Vierck, Jr., Department of Neuroscience, University of Florida College of Medicine, Gainesville, FL 32610

a Present address: Department of Neurosurgery, SUNY Health Science Center, 3118 Weiskotten Hall, Syracuse, NY 13210.

${ }^{h}$ Present address: Departments of Neurological Surgery and Neuroscience, University of Florida College of Medicine, Gainesville, FL 32610.

Copyright $\odot 1990$ Society for Neuroscience $0270-6474 / 90 / 072077-19 \$ 03.00 / 0$
}

and reflex responses clearly differed, indicating that different processes determined changes in these spinal and supraspinal reactions to nociceptive stimulation.

The surgical procedure known as anterolateral chordotomy has been used to relieve chronic pain in humans since the early part of this century (Spiller and Martin, 1912). The basis for pain reduction is commonly attributed to interruption of spinothalamic fibers in the ventrolateral white matter (Walker, 1940; Kuru, 1949), but other pathways in this region may contribute to pain sensitivity via projections to regions of the brain stem that communicate with the cercbrum (c.g., Bowsher, 1957; Mchler et al., 1960; Kerr, 1975; Boivie, 1979).

Chordotomy consistently reduces chronic pain for a period of weeks to months, producing significant or complete relief in approximately $90 \%$ of the patients. The occasional failures are likely to have resulted from incomplete lesions. However, some of the patients that initially experience a good result from chordotomy eventually report a return of chronic pain (e.g., White and Sweet, 1969). The basis for the return has not been established but does not appear to be a matter of incomplete lesions of the spinothalamic tract. Some patients who experience a return of chronic pain can be successfully relieved by a second, more extensive chordotomy (e.g., Kahn and Rand, 1952). However, this result is particularly likely in cases in which a rapid time course for sensory recovery parallels a reduction in edema of the spinal cord, as evidenced by a lowering of the upper segmental level of hypalgesia. Incomplete interruption of the spinothalamic tract does not explain recovery of chronic pain that can occur months or even years after surgery. In these cases, secondary chordotomy often has not been successful in reinstating relief from pain (White, 1963). Furthermore, other patients have experienced uninterrupted pain relief for years following interruption of only one portion of one anterolateral column (Nathan and Smith, 1979).

In order to understand and prevent the return of pain that can occur following anterolateral chordotomy, it is important to reveal relationships between anatomical and psychophysical findings. For this purpose, an animal model of pain reactivity is required, and a primate model is optimal, because the spinal pathways subserving nociception differ considerably among mammals (e.g., Giesler et al., 1981; Kemplay and Webster, 1986; Apkarian and Hodge, 1989a). Histological verification of each lesion is necessary for assessment of whether certain configurations or locations prevent recovery and others permit or promote reorganization. Furthermore, the incidence and onset of recovery are variable following chordotomy, and therefore frequent testing over long periods of time is needed to describe 
the time course of changes in nociceptive sensitivity for each subject. This is rarely feasible with human patients.

Previous reports have validated a testing procedure with $\mathrm{Ce}$ bus and Macaque monkeys (Vierck et al., 1971; Vierck and Luck, 1979; Greenspan et al., 1986), establishing behavioral measures that are reliable and appropriate for primate nociception and for the effects of chordotomy (Vierck et al., 1983a, b, 1986). The measures of nociception are derived from operant escape responses and are compared with reflex reactions to the same stimuli. The present report relates these measurements over time to the locus and extent of chordotomy.

\section{Materials and Methods}

Subjects. Eighteen adolescent pig-tailed monkeys ( $M$. nemestrina) were the subjects in this experiment. During training periods, the monkeys were provided food ad libitum in their home cages, and they received water during and after the experimental sessions. After training was complete, all but 4 animals received food and water ad libitum in their home cages. The remaining 4 received their water during and after the data collection sessions, as a consequence of the spccialized task they were trained to perform (see Greenspan et al., 1986), combining tests for escape and detection. The animals were maintained in animal care facilities fully accredited by the American Association for Accreditation of Laboratory Animal Care.

Stimulus. A BRS/LVE programmable (titrating) shocker provided 60 $\mathrm{Hz}$ alternating, constant current to the midlateral surface of either lower leg. The stimulation sites, which were within a cutaneous region supplied predominantly by the L6 and S1 dorsal roots (Kuhn, 1953), were tattooed to ensure consistent electrode placement. Stainless steel electrodes were placed over wells of conductive electrode paste, surrounded by foam pads, and securely taped. The surface area of each electrode-skin contact point was $10 \mathrm{~mm}^{2}$. The 2 wells on each leg were separated by $1 \mathrm{~cm}$. The current was interrupted $(40 \mathrm{msec}$ on, $200 \mathrm{msec}$ off) to limit sensory adaptation and to minimize the duration of nociceptive stimulation.

Behavioral procedure. A PDP 11/03-L computer controlled stimulus presentations, recorded and stored the response measures, and provided for the independent operation of 2 training/testing stations. The output of the stimulators was monitored by a Tektronix storage oscilloscope to verify that proper levels of current were delivered.

The behavioral measures of reactivity were derived from operant and reflexive responses on an escape task. The training process was gradual and consisted of 4 steps. Initially, the monkeys were trained to pull a manipulandum in order to receive approximately $1 \mathrm{ml}$ of water while seated in a Plexiglas chair constructed for this purpose. Next, a tone was periodically presented, and water was available only when the manipulandum was pulled during the tone period. When the monkeys began to respond preferentially to the tone, a low-intensity electrocutaneous stimulus (ES) was applied concomitant with the tone. A delay between the tone and the ES onset was introduced and gradually increased, and water delivery was contingent upon pulling the manipulandum when the ES was present. Over a period of weeks, the ES intensity was gradually increased, and then the tone and water were phased out. This procedure shaped the animals to pull the manipulandum to escape ES; the sole consequence of this response for trained animals was termination of the ES.

The ES intensities for trained animals were fixed at $0.1,0.4,1.1$, and $2.5 \mathrm{~mA} / \mathrm{mm}^{2}$. These intensities were chosen on the basis of human psychophysical studies conducted under similar conditions (Vierck et al., 1983b), and they spanned a range from below pain threshold through well-tolerated suprathreshold levels. The order of stimulus intensities was fixed in repetitive cycles of ascending and descending values, presenting 2 trials at each intensity per cycle (i.e., $0.1,0.4,1.1,2.5,2.5$, $1.1,0.4$, and $0.1 \mathrm{~mA} / \mathrm{mm}^{2}$ ). The fixed sequence of intensities does not significantly alter the function relating stimulus intensity to operant responsivity when compared to random sequencing (Vierck et al., 1983a). After a complete cycle on one leg, stimulation was switched to the opposite leg, and each session consisted of 4 cycles. The first trial was delivered to the left or right leg on alternate days.

Many aspects of this procedure were designed to minimize pain and stress for the animals. The monkeys were adapted to each variant of the experimental training before proceeding to the next. Nociceptive levels of stimulation were introduced gradually and only after the animals were fully trained to respond appropriately. At all times during the session the monkeys were able to terminate the stimulus by pulling the manipulandum, and they could limit the stimulus to one $40 \mathrm{msec}$ train of sinusoids. The parameters of ES in this study have been utilized previously for stimulation of the same cutaneous region of both humans and monkeys, and they have never produced observable tissue damage. All evoked sensations are brief and tolerable.

Response measures. Five measures of responsivity to ES were employed: force and latency of operant escape responses, frequency of intertrial manipulandum pulls and shifts of weight (general activity), and force of the hindlimb flexion reflex. When an animal pulled the manipulandum with either hand during the period of ES presentations, the trial was terminated. If the animal did not pull the manipulandum during the trial, the stimulus was terminated after $5 \mathrm{sec}$. Four animals were trained to pull the manipulandum once for escape. Fourteen monkeys were required to pull twice in succession in order to terminate the stimulus, in the expectation that the interval between pulls would reflect stimulus intensity. This proved not to be the case, and therefore only latencies to the second (escape) response were utilized for these animals.

The force of each pull was measured by a Statham-Gould force transducer, which was mounted behind the front panel of the testing apparatus. The electrical signal from this transducer was amplified and digitized. Each manipulandum pull was detected by a microswitch located on the front panel, and the latency to switch closure was measured relative to $\mathrm{ES}$ onset.

The force of reflexive leg flexions was monitored by means of another Statham-Gould force transducer, which measured the force transmitted by leg flexion to the seat of the chair. The dorsal surface of the thigh rested against a rigid surface, thus converting upward leg movement into a downward displacement of the seat. Reflexive flexion resulted in a transient force increase following ES presentation. To insure that the peak of this response was detected, the maximal force during the first $200 \mathrm{msec}$ of each trial was recorded as the reflexive response to $40 \mathrm{msec}$ of stimulation. The reflexive action depended primarily upon contraction of the iliopsoas muscle at the hip and not upon directly elicited twitches of the gastrocnemius muscles located beneath the electrodes on the calf. The reflexive responses were not instrumental in reducing the intensity or duration of ES.

In an attempt to evaluate whether general activity levels in the intertrial intervals were influenced by the intensity of preceding stimulation, a Schmitt trigger was set to detect moderate changes in voltage across the seat transducer. These intertrial events were sorted (1) according to the intensity of the preceding trial and (2) within 3 bins (10 $\mathrm{sec}, 40 \mathrm{sec}$, and then $10 \mathrm{sec}$ ) of the $60 \mathrm{sec}$ intertrial intervals. In addition, the number of bar pulls in each intertrial interval was counted and sorted by stimulus intensity and within the intertrial bins.

Surgical procedure. After a monkey had completed the training period, stabilized preoperative data were gathered for at least a month. Then a unilateral anterolateral chordotomy was performed under sterile conditions while the monkey was deeply anesthetized with methoxyflurane. Following dorsal laminectomy of 2 vertebrae, the right anterolateral tract was severed, attempting to produce a lesion extending dorsally beyond the dentate ligament and ventrally to the midline. Each lesion was at an upper thoracic level. After allowing 1 week for recuperation from the surgery, the daily testing routine was resumed.

Histology. Between 6 and 20 months after chordotomy, the monkeys were killed under deep pentobarbital anesthesia by intracardial perfusion with an aldehyde fixative. The area surrounding the lesion site was removed for subsequent histological treatment. Tissue from the first 10 monkeys was embedded in paraffin for sectioning and was stained with Luxol Fast blue. Tissue from the later monkeys was embedded in celloidin, and sections were alternately treated with Mahon and Nissl stains.

Data analysis. The operant responses on the escape task generated the following within-trial data: (1) the percentage of escape responses for each intensity, (2) the latency of the manipulandum pulls that terminated ES, and (3) the force of the first response during a trial. Escape frequency and latency were combined into a single measure of trial duration that was calculated as described previously (Vierck et al., 1983a; Greenspan et al., 1986). Briefly, trial duration consisted of the geometric mean of (1) latencies to escape the stimulus when a response occurred and (2) a maximal latency value for each trial on which no response occurred. The maximal latency value for no-response trials was determined for each animal as the 95 th percentile of the preoperative latency 


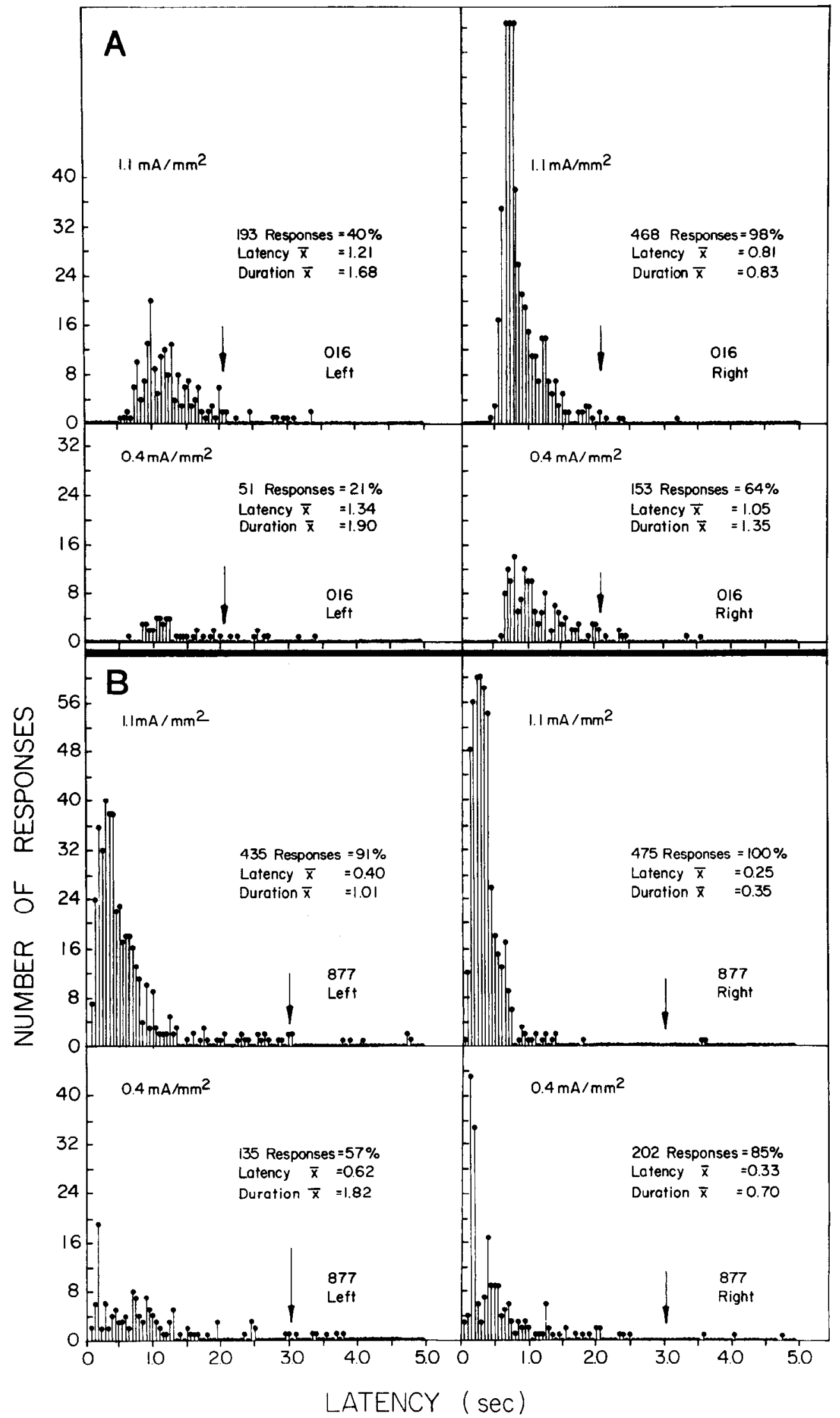

Figure 1. Distributions of early postoperative escape latencies are shown for 2 animals. The maximal latencies ( $a r-$ rows) were determined from preoperative escape responses of each animal and represented the 95 th percentile of latencies to the intensity just above escape threshold. This value differed among animals but for a given animal was consistently located near the end of each latency distribution, regardless of the stimulus intensity or the influence of a spinal lesion. The effect of decreasing nociception was to reduce the percentage of short-latency responses, but the overall length of the latency distribution remained relatively constant. This is seen for 2 intensities of stimulation on the right (ipsilateral and normal) or left (contralateral and affected) leg of animals \#016 $(A)$ and $\# 877(B)$. For each panel, the number and percentage of escape responses are indicated; the arithmetic mean of the response latencies is given; and the yeometric mean of the trial durations is listed. 
Figure 2. Average values for each measure of operant responsivity to electrocutaneous stimulation of each leg are shown for the preoperative period and for the first month of postoperative testing of 15 animals. For each measure, increased reactivity is represented by larger values. $A$, The percentage of trials on which a response occurred within $5 \mathrm{sec}$ of stimulus onset is plotted as a function of stimulus intensity. Thresholds for escape are indicated by intersection of the lower dashed line (at $50 \%$ ) with each function. $B$, The average trial durations at each intensity for each animal were subtracted from the maximal trial duration of that animal, and these values were averaged across the group of 15 animals. $C$. The forces of escape response were averaged for those trials on which escape responses occurred. $D$, The number of bar responses that occurred within $10 \mathrm{sec}$ after termination of each trial was averaged.

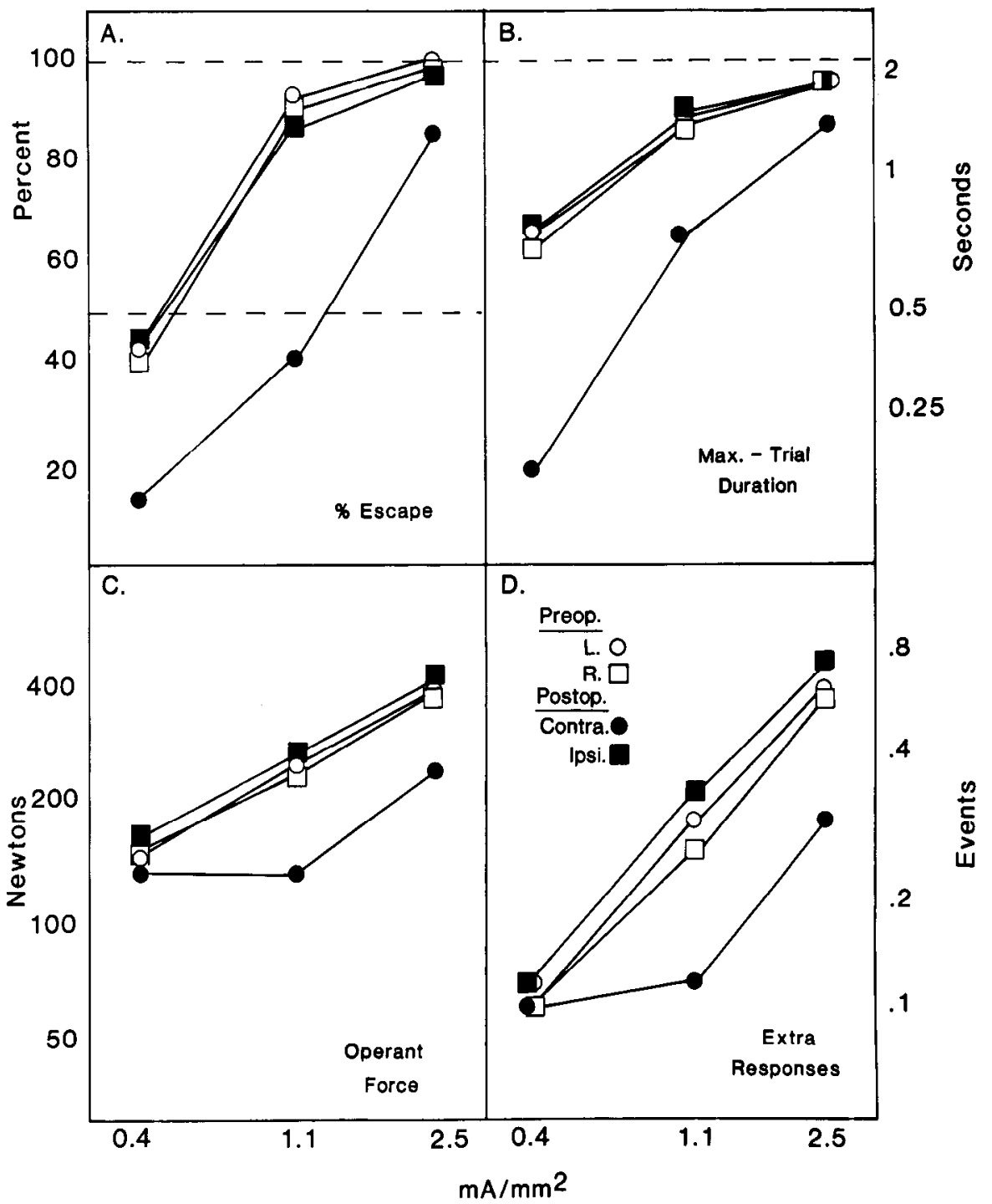

distribution for the intensity of stimulation that was just suprathreshold for cscape reactions (see Fig. 1). This measure of trial duration assesses response vigor over a wide sensory domain from threshold to suprathreshold intensities, by conservatively assigning no-response trials with maximal trial durations that are appropriately scaled to the upper limit of each animal's range of response latencies. In order to represent decreases in nociceptive reactivity as lower values on all response measures, trial durations are shown in the figures as the difference between the maximal trial durations and average trial durations (e.g., Fig. 2B).

Statistical comparisons of responses to a single stimulus intensity were made by Student's $t$-tests for 15 animals that were selected on the basis of appropriate lesions and recovery periods (see Fig. 13 and associated text for a description of the additional animals). Each test that involved multiple comparisons utilized Tukey's adjustment of the $t$-distribution. Statistical comparisons of responses to the different stimulus intensities utilized analyses of variance for repeated measures and unequal numbers of subjects.

\section{Results}

\section{Preoperative escape responses}

The response profiles on the escape paradigm before surgery were similar to those described elsewhere using nearly identical testing procedures (Vierck et al., 1971; Vierck and Luck, 1979; Cooper and Vierck, 1986). In addition, 4 animals in this study were trained on a variation of the paradigm that interspersed detection and escape trials in each session (Greenspan et al., 1986). This subgroup of animals (nos. 113, 103, 045, and 017) demonstrated that thresholds for escape $\left(0.7 \mathrm{~mA} / \mathrm{mm}^{2}\right.$ for these animals) were 2 orders of magnitude higher than thresholds for detection $\left(0.007 \mathrm{~mA} / \mathrm{mm}^{2}\right)$ of electrocutaneous stimulation of the same skin sites.

The principal measure of operant reactivity was trial duration, which reflects both the percentage and the latencies of escape responses (see Materials and Methods). Each animal (1) responded to increasing intensities of stimulation with a greater pcrcentage of escape responses (Fig. $2 A$ ) and (2) terminated trials more quickly as stimulus intensity increased (e.g., Fig. 1). Therefore, a plot of the maximal trial durations minus the actual trial durations produces values that increase with stimulus intensity and reflect relative speeds of responding (Fig. $2 B$ ). In addition, 14 animals escaped suprathreshold stimulation with greater force for increasing stimulus intensities (Fig. 2C); the other 4 animals escaped with nearly maximal force for all suprathreshold intensities, and therefore their escape forces were not useful for assessing the effect of chordotomy (Vierck and Cooper, 1984).

Ten animals made extra bar pulls after trial terminations (within the first intertrial bin), and this tendency was positively 
related to stimulus intensity (Fig. $2 D$ ). Otherwise, the animals rarely emitted intertrial bar pulls, and there was no relationship between stimulus intensity and the frequency of bar pulls in the last $50 \mathrm{sec}$ of the intertrial intervals (bins 2 and 3). The near absence of bar pulls in the last $10 \mathrm{sec}$ of the intertrial interval demonstrates that the animals did not make anticipatory responses in an attempt to time a response to the onset of ES.

For the measure of generalized activity (shifts of weight that were detected by the seat transducer), the only relationship with stimulus intensity was accounted for by movements related to bar pull activity in the first intertrial bin. That is, the intertrial activity measure did not contribute uniquely to the evaluation of behavioral reactions to stimulation at different intensities.

\section{Early effects of anterolateral chordotomy on operant responses}

For each animal the initial effect of chordotomy was to produce a contralateral decrease in nociception, as assessed by each operant response measure. Anterolateral chordotomy significantly decreased the percentage, speed, and force of responses to stimulation of the contralateral (left) leg (Fig. $2 A-C$ ). In contrast, each measure of operant reactivity to stimulation of the ipsilateral leg was unaffected by the lesion. The consistency of the animals' normal reactions to suprathreshold stimulation is demonstrated by the congruence of the curves relating each response measure to the stimulus intensities delivered to either leg preoperatively and to the ipsilateral leg postoperatively.

Ideally, the slopes of functions relating operant reactivity to the 4 stimulus intensities would indicate whether anterolateral chordotomy produced comparable decreases in sensory magnitude throughout the range of intensities delivered. Unfortunately, this analysis cannot be applied to any one operant measure because of response constraints for either the near-threshold or the high intensity. In general, trial durations were minimal in response to $2.5 \mathrm{~mA} / \mathrm{mm}^{2}$ (a ceiling effect), and escape forces were minimal or absent at $0.4 \mathrm{~mA} / \mathrm{mm}^{2}$ (a floor effect). However, a sense of whether the lesion decreased reactivity across intensities can be obtained from trial durations at 0.4 and 1.1 $\mathrm{mA} / \mathrm{mm}^{2}$ (Fig. $2 B$ ) and escape forces in response to 1.1 and 2.5 $\mathrm{mA} / \mathrm{mm}^{2}$ (Fig. 2C). Clearly, chordotomy decreased contralateral reactivity to each suprathreshold intensity, and this effect approximated a parallel shift across intensities, judging from the partial functions that were not limited by floor or ceiling effects. As a consequence of this generalized decrease in nociceptive reactivity, escape thrcsholds wcre clcvatcd from 0.51 $\mathrm{mA} / \mathrm{mm}^{2}$ preoperatively to $1.2 \mathrm{~mA} / \mathrm{mm}^{2}$ postoperatively for the left leg.

The 4 animals tested on the combined detection/escape paradigm demonstrated that the effect of anterolateral chordotomy was restricted to nociceptive thresholds (Greenspan et al., 1986). Averaged preoperative thresholds for detection of ES were 0.0075 and $0.0064 \mathrm{~mA} / \mathrm{mm}^{2}$ for stimulation of the left and right legs, and early postoperative thresholds were 0.0087 (contralateral $=$ left) and $0.0058 \mathrm{~mA} / \mathrm{mm}^{2}$. Consistent with the results for animals tested only on the escape paradigm, the spinal lesions elevated contralateral escape thresholds for the animals on the combined paradigm (from 0.71 to $1.66 \mathrm{~mA} / \mathrm{mm}^{2}$ compared to 0.72 and then $0.65 \mathrm{~mA} / \mathrm{mm}^{2}$ on the right).

\section{Long-term changes in escape behavior}

Changes in nociception over time were not necessarily revealed by operant responses to all intensities for each animal because of individual differences in response criteria. For instance, for
9/18 animals, preoperative escape thresholds were at or below $0.4 \mathrm{~mA} / \mathrm{mm}^{2}$, and the other half produced thresholds above 0.4 $\mathrm{mA} / \mathrm{mm}^{2}$. For the animals with thresholds above $0.4 \mathrm{~mA} / \mathrm{mm}^{2}$, decreases in reactivity following chordotomy would not be revealed by responses to that intensity (a floor effect). Conversely, animals with low thresholds usually responded maximally to the highest intensity, which eliminated the opportunity to observe increases in responsivity to this intensity over time (a ceiling effect). Therefore, changes in operant responses over time were evaluated for individual animals at a stimulus intensity that was least limited by floor or ceiling effects during the entire period of testing. The trial durations at the least limited intensity are shown in Figures 3 and 5 for each of the 15 animals that received the intended lesion of the right anterolateral column and were tested long enough to determine whether recovery of contralateral nociceptive reactivity occurred.

On the basis of trial durations, individual animals were classified as recovered (group $\mathrm{R} ; n=7$ ) or unrecovered (group U; $n=8$ ) from an early postoperative deficit, depending on whether there was a sustained return to control levels of operant reactivity. In order to evaluate this criterion statistically, early and late postoperative plateaus were identified for each animal by inspection of the trial durations shown in Figures 3 and 5. That is, 2 postoperative plateaus were identified for each animal: (1) an early period in which the trial durations for stimulation of the contralateral leg were high and (2) a late period of stabilized trial durations that included the last postoperative values obtaincd. Comparisons of cach animal's trial durations within the preoperative, early postoperative, and late postoperative periods are presented in Tables 1 and 2.

Table 1 lists ratios of trial durations that reveal lesion effects on operant reactivity for each animal that recovered (group R). Ratios $>1$ indicate decreased operant reactivity for the leg and plateau period listed in the numerator (e.g., longer trial durations for early postoperative stimulation of the contralateral leg/shorter durations for the ipsilateral leg). The control values listed in the denominators of these ratios include preoperative trial durations from stimulation of either leg or postoperative responses to stimulation of the ipsilateral leg.

The average trial durations over 2 week portions of the postoperative plateau periods provided repeated measures that were utilized to test for the presence or absence of recovery for individual animals. Statistical evaluations of recovery for each animal werc adjusted for multiple comparisons among the 2 postoperative periods and the 2 limbs. Statistical comparisons of postoperative and preoperative performance of individual animals were not made because long periods of stabilized preoperative performance were not available. However, ratios of postoperative to preoperative performance are included in the tables to document on an individual basis the correspondence of trial durations for either leg preoperatively and the ipsilateral leg in the early postoperative period (as shown in Fig. 2).

Recovery of nociception by each of 7 animals (group R) is indicated by the following comparisons: (1) Trial durations for early postoperative stimulation of the contralateral (left) leg ranged from 1.24 to 2.04 times preoperative durations (row 1 of Table 1), but the late postoperative/preoperative ratios for the contralateral side ranged from 0.51 to 1.07 (row 4). (2) A similar comparison of early contralateral/early ipsilateral ratios (row 2) versus late contralateral/early ipsilateral ratios (row 5) produced nonoverlapping ranges (1.42-2.04 vs $0.54-1.18)$. Additionally, these comparisons revealed a progression from sta- 

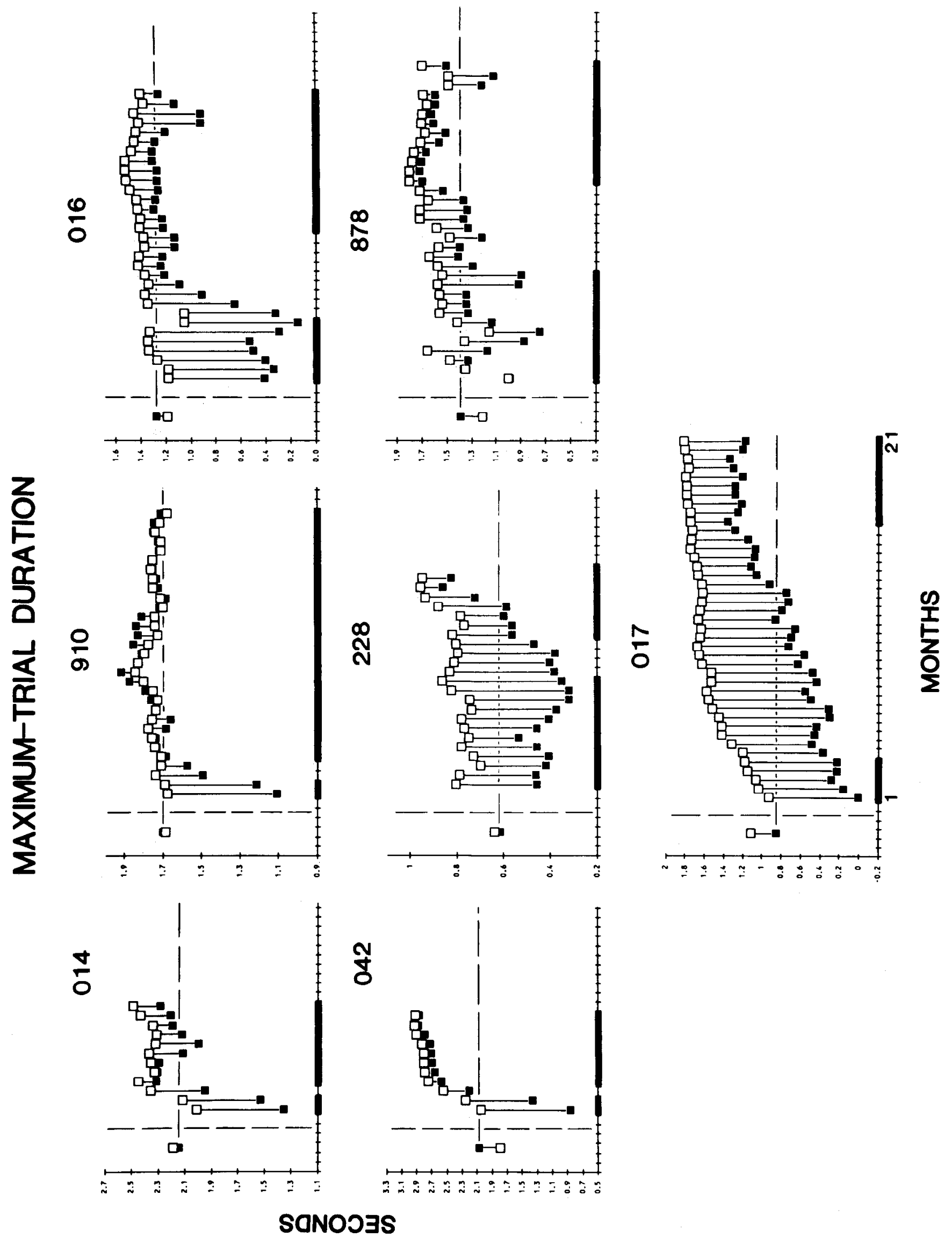
Table 1. Ratios of trial durations in different testing periods for individual animals in group $\mathbf{R}$

\begin{tabular}{|c|c|c|c|c|c|c|c|c|}
\hline \multirow[b]{2}{*}{ Comparison } & \multirow[b]{2}{*}{ Mean } & \multicolumn{7}{|c|}{ Group R } \\
\hline & & $\# 878$ & $\# 910$ & $\# 016$ & $\# 228$ & $\# 014$ & $\# 042$ & $\# 017$ \\
\hline 1. Early contra./preop. contra. ${ }^{a}$ & 1.58 & 1.34 & 1.67 & 2.04 & 1.24 & 1.48 & 1.86 & 1.45 \\
\hline \multirow[t]{2}{*}{ 2. Early contra./early ipsi. } & 1.70 & 1.54 & 1.70 & 2.04 & 1.51 & 1.42 & 2.00 & 1.67 \\
\hline & & $<0.05$ & NS & $<0.01$ & $<0.01$ & $<0.05$ & $<0.01$ & $<0.01$ \\
\hline \multirow[t]{2}{*}{ 3. Early contra./late contra. } & 2.57 & 1.89 & 1.90 & 1.90 & 1.29 & 1.57 & 3.64 & 1.97 \\
\hline & & $<0.05$ & $<0.01$ & $<0.01$ & $<0.01$ & $<0.01$ & $<0.01$ & $<0.01$ \\
\hline 4. Late contra./preop. contra. ${ }^{a}$ & 0.83 & 0.72 & 0.88 & 1.07 & 0.96 & 0.94 & 0.51 & 0.74 \\
\hline \multirow[t]{2}{*}{ 5. Late contra./early ipsi. } & 0.89 & 0.82 & 0.89 & 1.07 & 1.18 & 0.91 & 0.54 & 0.85 \\
\hline & & NS & NS & NS & NS & NS & $<0.01$ & NS \\
\hline \multirow[t]{2}{*}{ 6. Late contra./late ipsi. } & 1.29 & 1.19 & 0.96 & 1.35 & 1.36 & 1.14 & 1.16 & 1.84 \\
\hline & & NS & NS & $<0.01$ & NS & NS & NS & $<0.01$ \\
\hline 7. Early ipsi./preop. ipsi. ${ }^{a}$ & 0.95 & 0.88 & 0.97 & 0.91 & 0.84 & 1.08 & 0.93 & 1.04 \\
\hline \multirow[t]{2}{*}{ 8. Late ipsi./early ipsi. } & 0.71 & 0.68 & 0.93 & 0.80 & 0.87 & 0.79 & 0.47 & 0.46 \\
\hline & & NS & NS & $<0.01$ & NS & $<0.05$ & $<0.01$ & $<0.01$ \\
\hline 9. Late ipsi./preop. ipsi ${ }^{a}$ & 0.65 & 0.50 & 0.90 & 0.72 & 0.72 & 0.86 & 0.38 & 0.48 \\
\hline
\end{tabular}

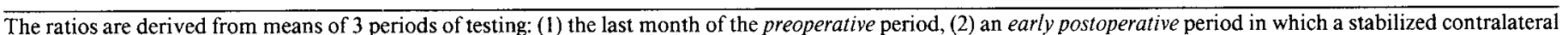

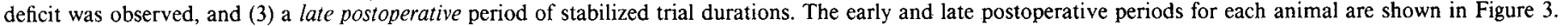

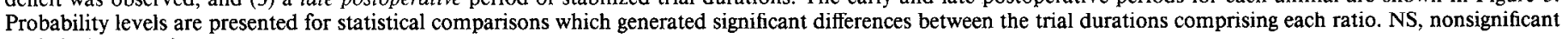
statistical comparisons.

a Post- to preoperative comparisons were not tested statistically.

tistical significance (early contralateral vs ipsilateral) to insignificance (late contralateral vs early ipsilateral). In fact, trial durations were significantly lower for late contralateral stimulation of one animal (\#042). (3) For each animal, the early contralateral durations were significantly greater than the late postoperative values for stimulation of the same side (row 3; ratios of 1.29-3.64 for early/late). This important comparison demonstrates a significant decrease in operant reactivity over the postoperative testing period with stimulation contralateral to anterolateral spinal lesions. (4) For 5 of the 7 animals, the late contralateral and late ipsilateral trial durations were not significantly different (row 6; ratios of 0.96-1.36), demonstrating a change from a significant early difference between left and right sides (row 2) to no difference. For the remaining 2 animals (nos. 016 and 017), the significant difference between sides in the late postoperative period resulted from increased ipsilateral reactivity. That is, the late/early ipsilateral ratios were significantly less than 1.0 for these animals (row 8).

Figure 4 presents averaged plateau values for the group of animals that recovered operant reactivity. For these 7 animals, responses to contralateral stimulation remained maximally decreased for an average of 12.3 weeks after anterolateral chordotomy. During this early postoperative period, trial durations for ipsilateral stimulation were similar to preoperative values. For the next 14.6 weeks, there was an increase in operant reactivity for postoperative stimulation of both legs of group $R$ animals. At an average of 26.9 weeks after surgery, maximal recovery had occurred, and performance was relatively stable with repcatcd testing for a mean of 16.6 additional weeks. The unconnected dots in Figure 4 indicate that the times of highest postoperative responsivity were at 40 and 42 weeks for the ipsilateral and contralateral sides.

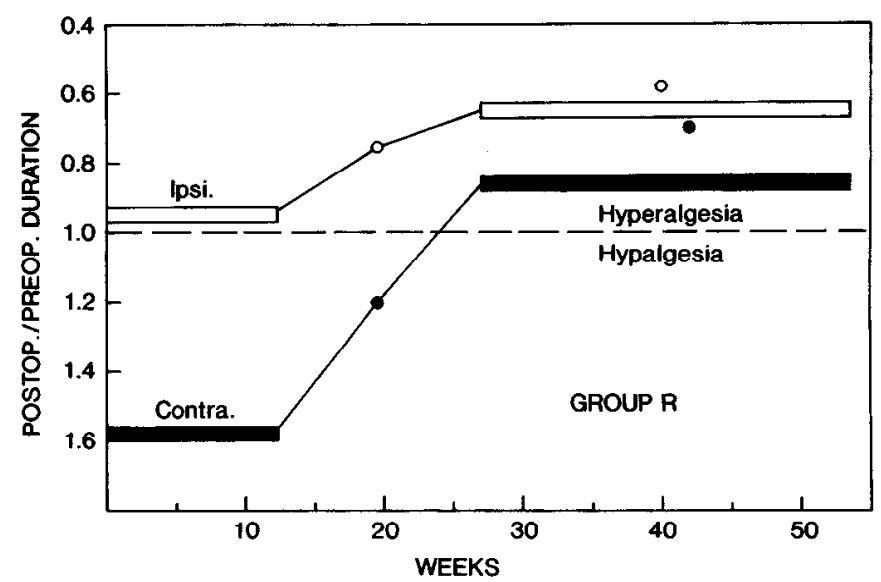

Figure 4. Mean ratios of postoperative/preoperative trial durations for group $R$ are shown for the early and late postoperative periods. The average lengths of the early and late periods are depicted by the horizontal extent of the bars. The connected points give the mean ratios for all sessions intervening between the early and later periods. The unconnected points depict the average timing and value of the biweekly period with the smallest ratio (i.e., at the point of greatest recovery). Ratios greater than 1.0 indicate hypalgesia, and ratios less than 1.0 indicate hyperalgesia, relative to preoperative performance.

\section{$\leftarrow$}

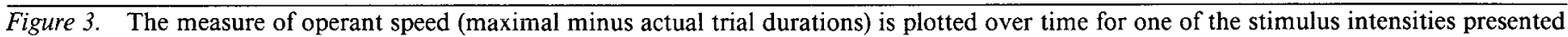

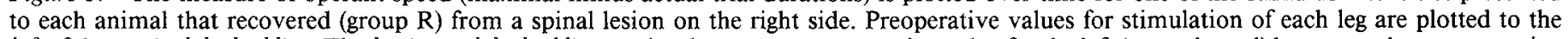

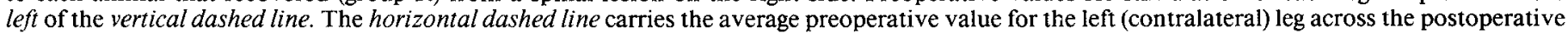

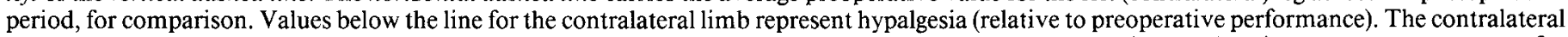

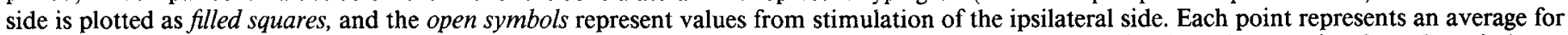

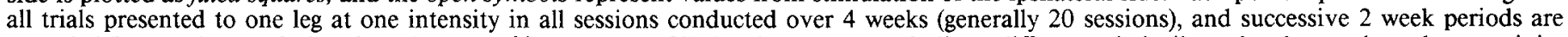

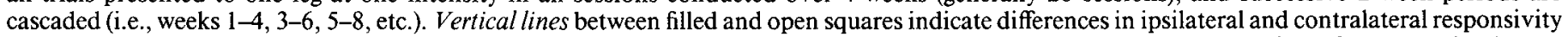
during 1 month periods. The thick bars on the abscissa represent the early and late postoperative periods that were defined for each animal. 

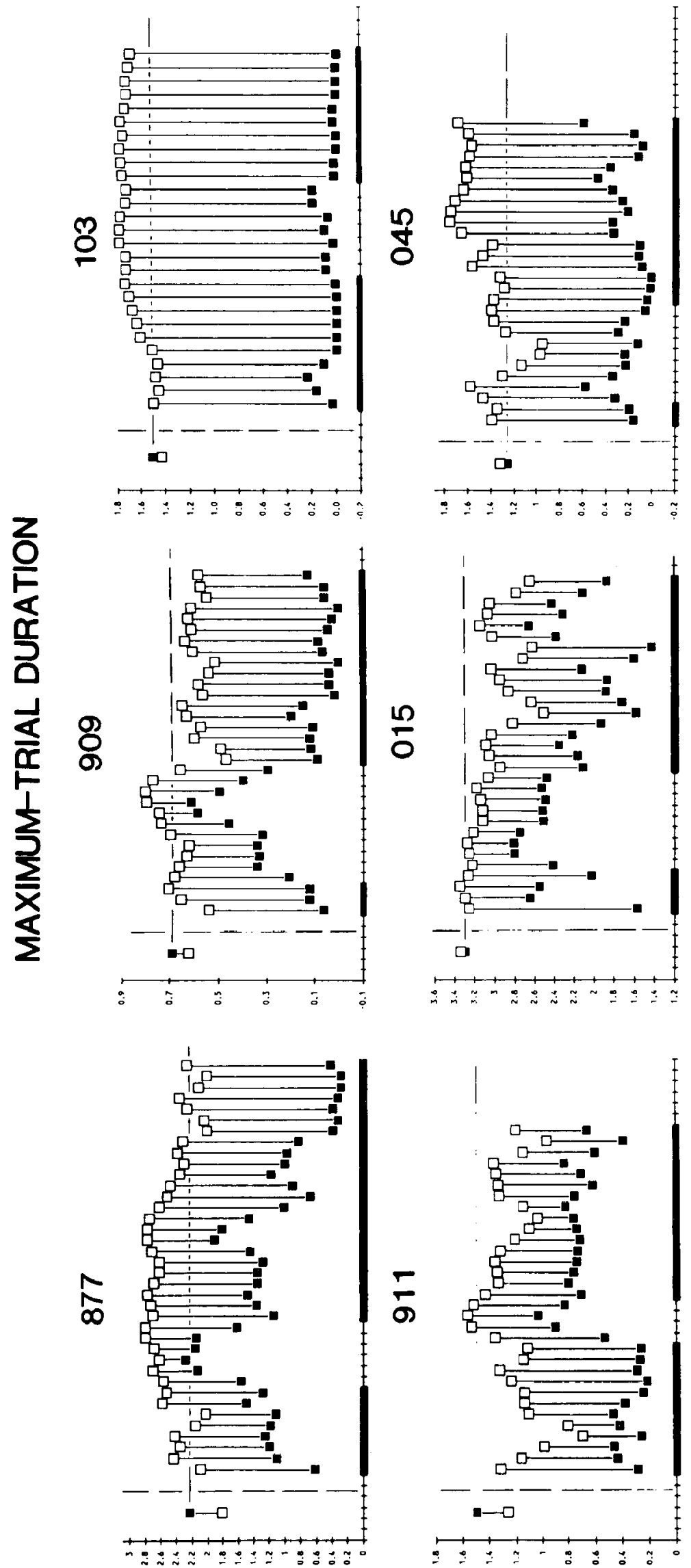
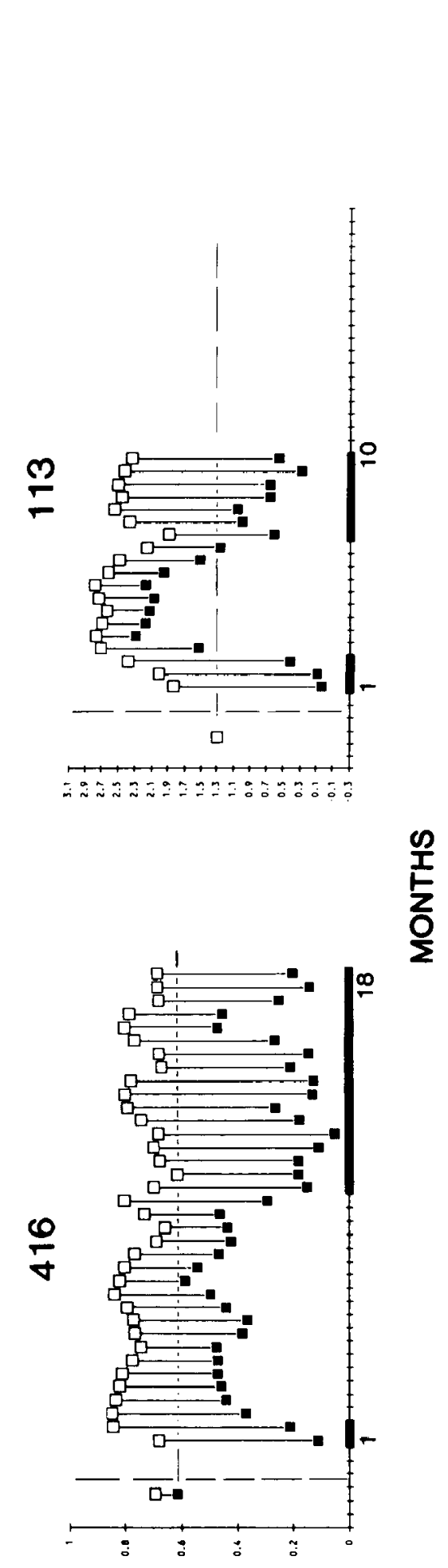
Table 2. Ratios of trial durations in different testing periods for individual animals in group $\mathrm{U}$

\begin{tabular}{|c|c|c|c|c|c|c|c|c|c|}
\hline \multirow[b]{2}{*}{ Comparison } & \multirow[b]{2}{*}{ Mean } & \multicolumn{8}{|c|}{ Group U } \\
\hline & & $\# 015$ & $\# 045$ & $\# 103$ & $\# 113$ & $\# 416$ & $\# 877$ & $\# 909$ & $\# 911$ \\
\hline 1. Early contra./preop. contra. ${ }^{a}$ & 2.11 & 2.87 & 1.69 & 2.55 & 1.50 & 1.66 & 2.34 & 2.02 & 2.22 \\
\hline \multirow[t]{2}{*}{ 2. Early contra./early ipsi. } & 2.23 & 2.83 & 1.79 & 2.79 & 2.40 & 2.01 & 2.59 & 1.80 & 1.65 \\
\hline & & NS & $<0.01$ & $<0.01$ & $<0.01$ & $<0.05$ & $<0.01$ & $<0.01$ & $<0.01$ \\
\hline \multirow{2}{*}{ 3. Early contra./late contra. } & 1.05 & 1.01 & 1.03 & 0.98 & 1.18 & 1.03 & 0.93 & 0.99 & 1.26 \\
\hline & & NS & NS & NS & NS & NS & NS & NS & $<0.05$ \\
\hline 4. Late contra./preop. contra. ${ }^{a}$ & 2.04 & 2.84 & 1.64 & 2.60 & 1.28 & 1.62 & 2.52 & 2.03 & 1.77 \\
\hline \multirow[t]{2}{*}{ 5. Late contra./early ipsi. } & 2.16 & 2.80 & 1.74 & 2.84 & 2.04 & 1.96 & 2.80 & 1.82 & 1.31 \\
\hline & & $<0.01$ & $<0.01$ & $<0.01$ & $<0.01$ & $<0.01$ & $<0.01$ & $<0.01$ & $<0.05$ \\
\hline \multirow[t]{2}{*}{ 6. Late contra./late ipsi. } & 2.28 & 1.77 & 2.00 & 3.34 & 2.42 & 1.90 & 3.70 & 1.71 & 1.42 \\
\hline & & $<0.01$ & $<0.01$ & $<0.01$ & $<0.01$ & $<0.01$ & $<0.01$ & $<0.01$ & $<0.01$ \\
\hline 7. Early ipsi./preop. ipsi. ${ }^{a}$ & 0.89 & 1.08 & 0.99 & 0.84 & 0.64 & 0.92 & 0.60 & 1.00 & 1.09 \\
\hline \multirow[t]{2}{*}{ 8. Late ipsi./early ipsi. } & 0.99 & 1.58 & 0.87 & 0.85 & 0.84 & 1.04 & 0.76 & 1.06 & 0.92 \\
\hline & & NS & NS & NS & NS & NS & NS & NS & NS \\
\hline 9. Late ipsi./preop. ipsi. ${ }^{a}$ & 0.91 & 1.70 & 0.86 & 0.72 & 0.51 & 0.95 & 0.46 & 1.08 & 1.00 \\
\hline
\end{tabular}

The early and late postoperative periods for each animal are shown in Figure 5. See note of Table 1. NS, nonsignificant statistical comparisons.

${ }^{a}$ Comparisons were not tested statistically.

The increase in operant reactivity over the postoperative testing period was greatest for contralateral stimulation of animals in group $\mathrm{R}$, progressing from a substantial deficit to slight hyperalgesia. However, reactivity also increased for ipsilateral stimulation, generating a late postoperative/preoperative ratio of 0.65 . For 4 of the 7 animals, the late postoperative trial durations were significantly less than the early postoperative values for the ipsilateral leg (row 8 of Table 1). Thus, the means of late postoperative trial durations, after performance had stabilized, revealed (1) a loss of the early hypalgesia for the left side and (2) development of an apparent hyperalgesia for the right side.

Table 2 lists the averaged ratios of trial durations for 8 animals that did not recover from an early postoperative deficit with contralateral stimulation (group U; Fig. 5). For these animals the contralateral deficit was revealed by early postoperative/ preoperative ratios of 1.50-2.87 (row 1 of Table 2) and early postoperative ratios for contralateral/ipsilateral performance of 1.65-2.83 (row 2). Similarly, the ratios of contralateral values in the late postoperative period to the different control values were 1.28-2.84 (row 4 of Table 2), 1.31-2.84 (row 5), and 1.423.70 (row 6). The statistical comparisons of late contralateral to early or late ipsilateral values were significant in each case. Also, the ratios of early contralateral to late contralateral values indicated little or no change during the postoperative testing period (ratios of 0.93-1.26; row 3 of Table 2).

The average ratios of postoperative to preoperative operant reactivity for group $U$ are shown in Figure 6. The early plateau of contralateral hypalgesia was similar in duration (averaging 13 weeks) to that of group R. This period of substantial deficit (postoperative/preoperative trial duration ratio of 2.11) was followed for most animals by a temporary recovery that progressed to a minimal postoperative/preoperative ratio of 1.17 for the contralateral leg. The phasic recovery peaked at an average of 23.3 weeks. At this point in time, the recovery process for group $U$ looked similar to that of group $R$. The right side became temporarily hyperalgesic as operant reactivity approached normal levels for stimulation of the left leg (see Fig. 6). Then, with extended testing of these animals, trial durations for both sides returned to levels comparable to the early postoperative peri- od-resulting in a slight increase in operant reactivity (over preoperative levels) on the ipsilateral side and a substantial hypalgesia on the side contralateral to the lesion. The late postoperative/preoperative trial duration ratio averaged 2.04 for the late plateau with contralateral stimulation. The late plateau began at an average of 28.8 weeks and continued for an additional 34.2 weeks.

Having defined groups $R$ and $U$ on the basis of a withinsubjects analysis of trial durations at the stimulus intensity that produced the least limited responses, between-subjects comparisons of these groups by analysis of variance provided an evaluation of group differences in responsivity to all stimulus intensities. Figure 7 presents trial durations for stimulation of the contra- and ipsilateral sides of animals in groups $\mathrm{R}$ and $\mathrm{U}$. The pancls on the left show that (1) contralateral reactivity was significantly reduced across intensities for both groups in the early postoperative period and (2) the late postoperative reactivity was similarly and significantly reduced for group $U$ but not group $\mathrm{R}$. The panels on the right depict no change in operant reactivity of group $U$ for ipsilateral stimulation, but a significant

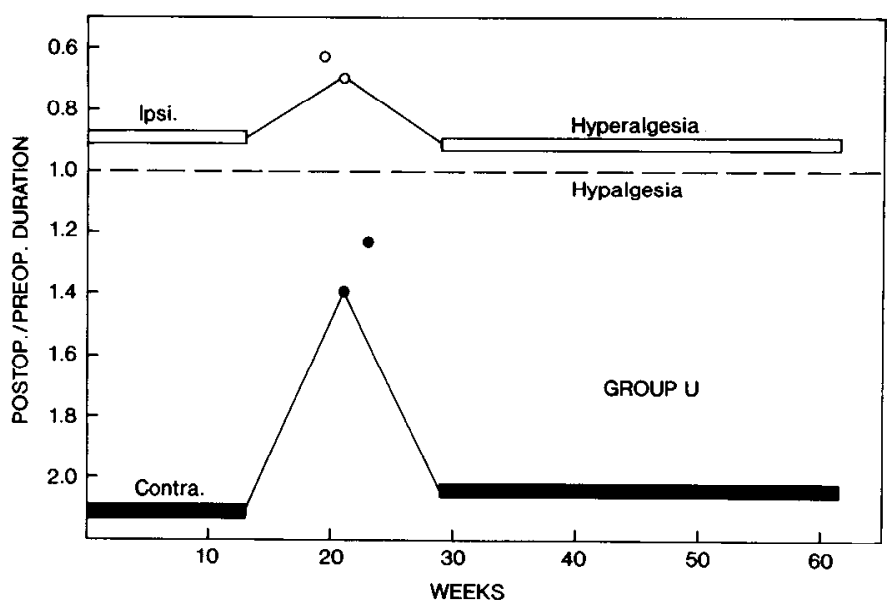

Figure 6. Mean ratios of postoperative/preoperative trial durations for group $U$ are shown for the early and late postoperative periods. See legend to Figure 5 for format. 


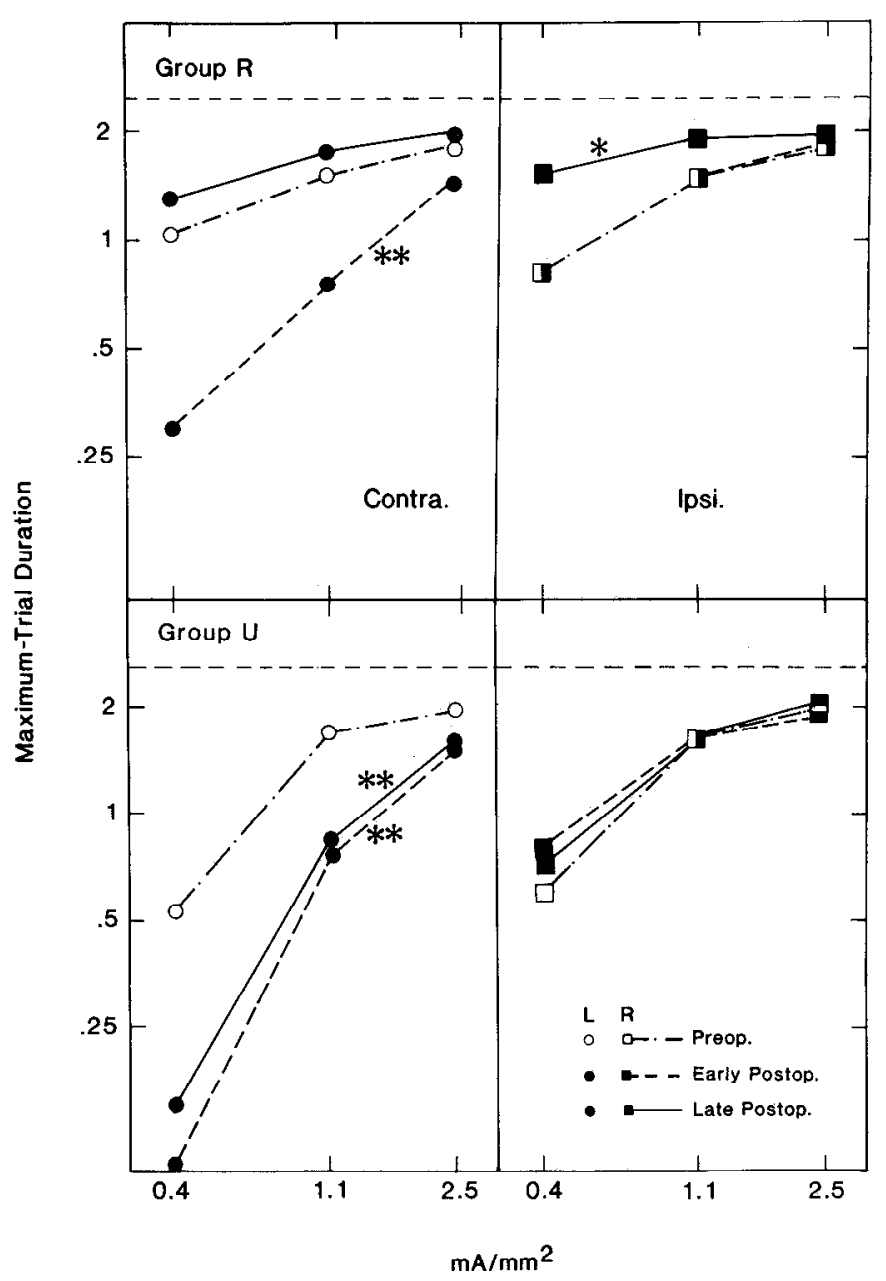

Figure 7. Averaged functions relate speed of escape (maximal trial durations - actual trial durations) to ES intensity for stimulation on the contra- or ipsilateral side of animals in groups $\mathbf{R}$ and U. Significant postoperative to preoperative comparisons are indicated by asterisks ( $p<0.05 ;{ }^{* *} p<0.01$ ). For group R (upper panels), contralateral hypalgesia was observed for the early postoperative period, and ipsilateral hyperalgesia was obtained for the late period. For group U (lower panels), contralateral hypalgesia was observed for the early and late periods, and ipsilateral changes were not seen.

hyperreactivity was detected for ipsilateral stimulation of group $\mathrm{R}$ during the late postoperative period. Thus, the ipsilateral hyperalgesia that was demonstrated on an individual basis for 4 of 7 animals in group R (Table 1) is also significant when late postoperative trial durations of the group are compared with preoperative or early postoperative values.

Similar effects are revealed by analysis of the operant forces of animals that responded differentially in the preoperative period to the different stimulus intensities (6 each in groups $R$ and $\mathrm{U})$. Figure 8 reveals significant reductions in escape force for both groups in the early postoperative period with stimulation of the left leg. This difference was maintained throughout the testing period for group $\mathrm{U}$, but operant force recovered for group $\mathrm{R}$. There was a suggestion of hyperalgesia (increased response force) in the late postoperative period for group $\mathrm{R}$, but this was not a statistically significant effect.

\section{Lesion locations and configurations}

Camera lucida reconstructions of the maximal extent of lesions for animals in group $\mathrm{R}$ are shown in Figure $9 \mathrm{~A}$. Each of these

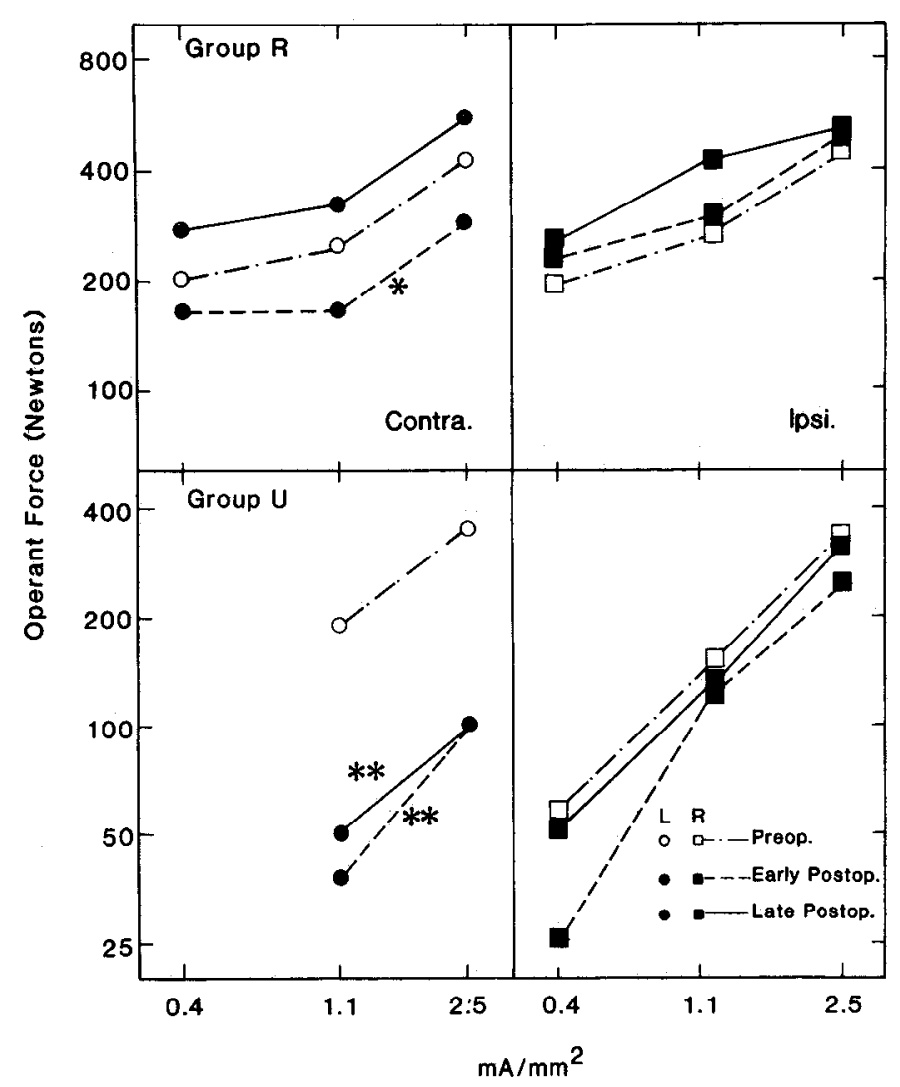

Figure 8. Averaged functions relate the force of escape responses to FS intensity for stimulation on the contra- or ipsilateral side of animals in groups $\mathrm{R}$ and $\mathrm{U}$ ( $n=6$ in each group). Significant contralateral decreases in operant response force $\left({ }^{*} p<0.05\right.$; $\left.{ }^{* *} p<0.01\right)$ were observed for group $\mathrm{R}$ in the early, but not the late, postoperative period (upper-left panel) and for group $U$ in the early and late periods (lowerleft panel).

lesions completely interrupted the right anterolateral column and extended medially, beyond the superficial location of the majority of spinothalamic tract axons (Applebaum et al., 1975). The largest lesion was that of $\# 017$, interrupting both ventral columns, both ventral horns, and all of the right lateral column, except for a small medial and dorsal portion of the dorsolateral column. Three other lesions interrupted both ventral columns (nos. 042, 014, and 016), and 2 additional lesions involved all of the right ventral column (nos. 910 and 878). Each lesion of group $\mathrm{R}$ animals extended dorsally to at least the midpoint of the right lateral column.

Reconstructions of the maximal extent of the lesions for group $\mathrm{U}$ animals are shown in Figure $9 B$. These lesions fell into 2 categories (separated by the line in Fig. $9 B$ ). The lesions for 5 animals were extensive and similar to those of group $R$ animals. Among this large lesion subgroup, 4 lesions interrupted both ventral columns, but one lesion (\#416) spared most of the ventral columns. Each large lesion of group $U$ extended medially to involve one or both ventral horns and dorsally to at least the midpoint of the right lateral column. In general, these lesions were more extensive medially and ventrally than the lcsions of group $\mathrm{R}$ animals, but this was not an absolutely distinguishing feature (see nos. 042, 014, and 017 in Fig. 9 $A$ ). The lesions of groups $\mathrm{R}$ and $\mathrm{U}$ did not differ in dorsolateral extent.

For a subgroup of 3 unrecovered animals, superficial lesions 
A
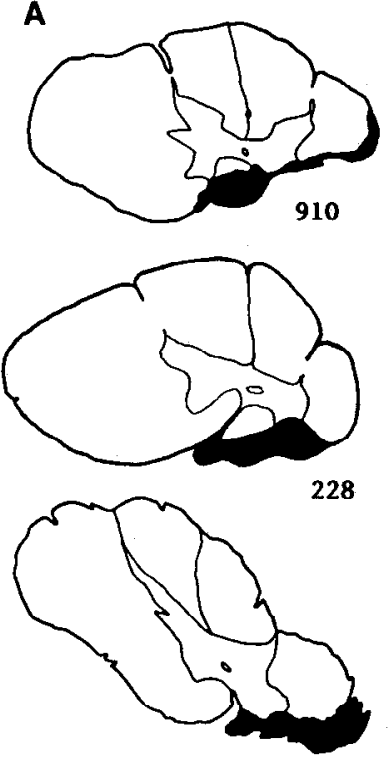

878
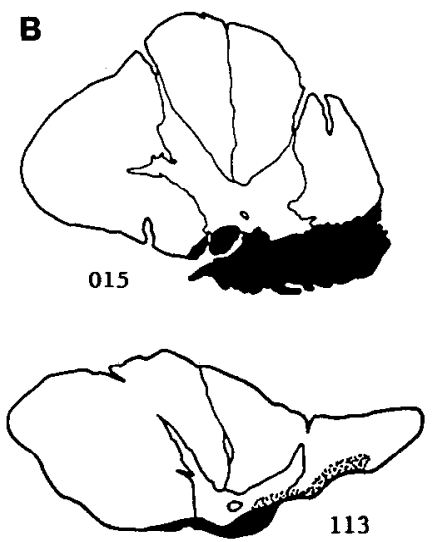

113
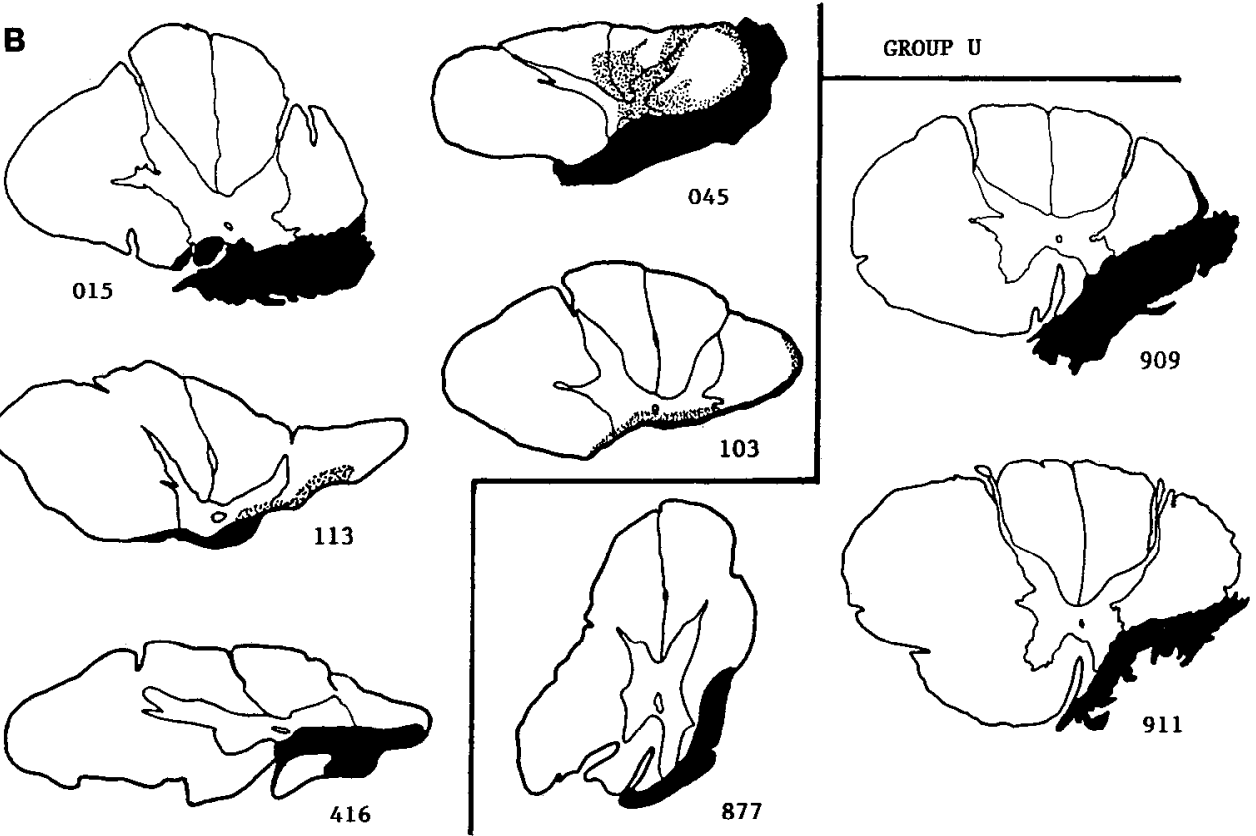

GROUP $\mathbf{R}$

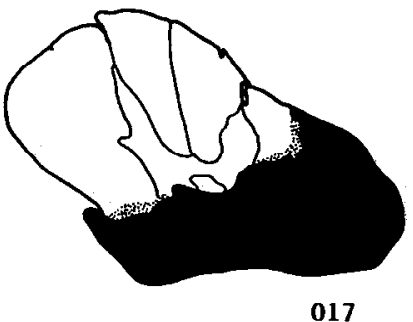

017
Figure 9. Camera lucida drawings of sections through the maximal extent of each spinal lesion received by animals in group $\mathrm{R}(A)$ and group $\mathrm{U}(B)$. Normal tissue is outlined; scar tissue is represented by black regions; and areas of gliosis that extend beyond the border of the scar are indicated by stippling. of the right anterolateral and ventral columns were distinctly smaller than the other 5 lesions in group U. These lesions (of nos. 909, 911, and 877; Fig. 9B, right) were strictly unilateral and did not appreciably invade the right ventral horn. Thus, after classifying the animals in 2 distinct catcgories on the basis of recovery of operant reactivity, histological evaluation revealed close similarity in the location and size of spinal lesions for the majority of animals, excepting 3 lesions in group $U$ that were restricted entirely to the anterolateral column on the right side.

\section{Long-term changes in reflexive behavior}

Consistent with previous descriptions of the amplitude of reflexes elicited by ES of the lateral calf (Cooper and Vierck, 1986; Greenspan et al., 1986), the force of leg flexion was directly related to stimulus intensity, but the slope of this function was low for stimulus intensities within the pain sensitivity range. Thus, the measure of reflex amplitude does not accurately reflect the increase in magnitude of pain sensations produced by these stimulus intensities. Also, the effect of anterolateral chordotomy on reflex force was distinctly different from the effect on operant reactivity to the same stimuli.

As summarized in Figure 10, the amplitude of the reflex response was significantly decreased bilaterally in the early postoperative period for the animals in both groups $\mathrm{R}$ and $\mathrm{U}$. The early postoperative effects did not differentiate between groups $\mathrm{R}$ and $\mathrm{U}$, but the pattern of reflex recovery did distinguish between the 2 groups. Thus, the reflex measure confirms the separation of animals on the basis of the presence or absence of recovery of operant reactions.

Reflex strength recovered bilaterally for group R. During the late postoperative period, the contralateral (left) response had 


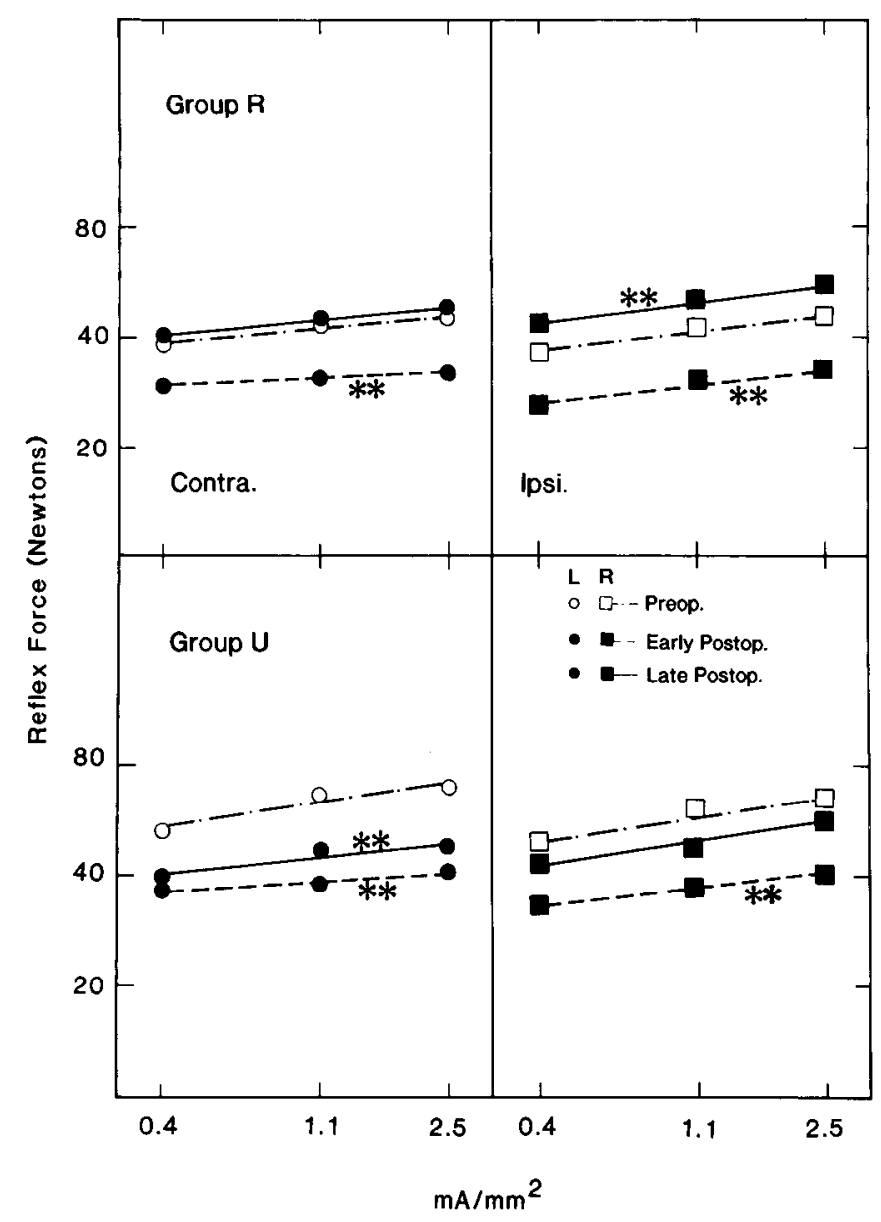

Figure 10. Averaged functions relate the force of flexion reflexes in response to different ES intensities delivered to the contra- or ipsilateral leg of the animals in groups $\mathrm{R}$ and $\mathrm{U}$. The early postoperative forces were significantly decreased for both legs and both groups $(* * p<0.01)$. The late postoperative forces remained decreased only for the contralateral leg of group U (lower-left panel); and recovery to significantly increased forces occurred only for the ipsilateral leg of group R (upperright panel).

returned to preoperative levels, and the ipsilateral response had increased to values that were significantly greater than preoperative forces for the right leg (Fig. 10, upper panels). In contrast, (1) contralateral reflex strength remained significantly decreased for group $\mathrm{U}$ animals (Fig. 10, lower panels), and (2) ipsilateral reflex strength in the late postoperative period for group $U$ was not significantly different from preoperative levels.

In general, the recovery of reflex force progressed gradually over the long postoperative recovery period, and for each animal the rate of recovery was similar for the 2 legs. Often, the pattern of reflex recovery for an animal differed considerably from the time course of changes in operant responsivity to the same stimuli. Thus, the recovery processes for a flexion reflex and for a long tract function progress at different rates. Also, the bilateral effect of the lesion on reflex vigor differs from a unilateral effect on nociceptive sensations.

\section{Comparisons of unilateral and bilateral lesions}

Because the purpose of this study was to evaluate recovery of function following complete interruption of the spinothalamic tract, the lesions extended dorsal to the dentate ligament, and interruption of the ventral column on the right was intended. Histological analysis revealed that 9 lesions involved most or all of both ventral columns, and 6 animals received strictly unilateral involvement of the lateral and ventral columns (see Fig. 9). Thus, comparison of the behavioral effects for these groups of animals has the potential to reveal functions of the ventral column. The group averages were derived from ratios of postoperative to preoperative performance for 1 month following and preceding surgery. For trial durations, the unilateral and bilateral lesions produced hypalgesia of equal magnitude on the left side (trial duration ratios of 1.89 and 1.95 , respectively), and no difference was observed for the right side (trial duration ratios of -0.96 and -0.98 for unilateral vs bilateral lesions). These comparisons indicate that interruption of the left ventral column did not (1) produce a contralateral effect on operant responsivity to nociceptive stimulation on the right or (2) add to the hypalgesia on the left from a right lateral and ventral lesion.

In contrast, as indicated by Figure 11 , the effects of unilateral and bilateral lesions differed for the flexion reflex. Unilateral lesions clearly produced a contralateral decrease in reflex force, but the ipsilateral effect was less pronounced. This lower contralateral than ipsilateral reflex force was statistically significant $(p<0.01)$ for 3 of the 4 animals with unilateral lesions. However, involvement of both ventral columns produced large decreases in reflex force for both hindlimbs. The paired comparisons over 5.5 months for the 9 animals with bilateral interruption of the ventral columns yielded 3 significant effects: 2 cases of lower reflex forces on the left and 1 animal with smaller responses on the right side. Although larger sample sizes and more restricted lesions will be required to determine the relative importance of the anterolateral and ventral columns for production of lateralized hyporeflexia, these results are highly suggestive of an important role for the ventral columns in reflex modulation.

\section{Skin lesions following chordotomy}

During the first 2-3 postoperative months, some of the monkeys developed a small $\left(<1 \mathrm{~cm}^{2}\right)$ skin lesion on the lower limb contralateral to the chordotomy. These lesions did not appear to be self-inflicted, and the monkeys were rarely observed to touch or attend to the skin lesion. Usually, the lesions disappeared within a few weeks without intervention on our part. Four monkeys, however, did pick or mouth a lesion on the contralateral leg (nos. 016, 228, 232, and 345). In one case (\#232), it was a single bout during the second postoperative month, which resolved without intervention. For the other 3 cases, the behavior was thwarted by applying antibiotic and quinine-treated bandages to the site. This regimen allowed for recovery of the skin lesions. In only one case was the skin lesion near the ES site, necessitating a break in the testing schedule.

There was not a clear relationship between the occurrence of skin lesions and changes in performance on the cscapc task. Only 2 of the animals in group $\mathrm{R}$ attended to skin lesions. Animal \#345 developed a skin lesion in the 5 th postoperative month, which was before recovery of operant reactivity. This animal developed and attended to subsequent lesions in the 13 th and 14th postoperative months, after operant recovery had occurred. Monkey \#016 exhibited recovery of escape responses in the 4 th postoperative month, but a cutaneous lesion did not appear until the 6 th postoperative month. Another animal (\#232) attended to a contralateral skin lesion in the 2 nd postoperative 


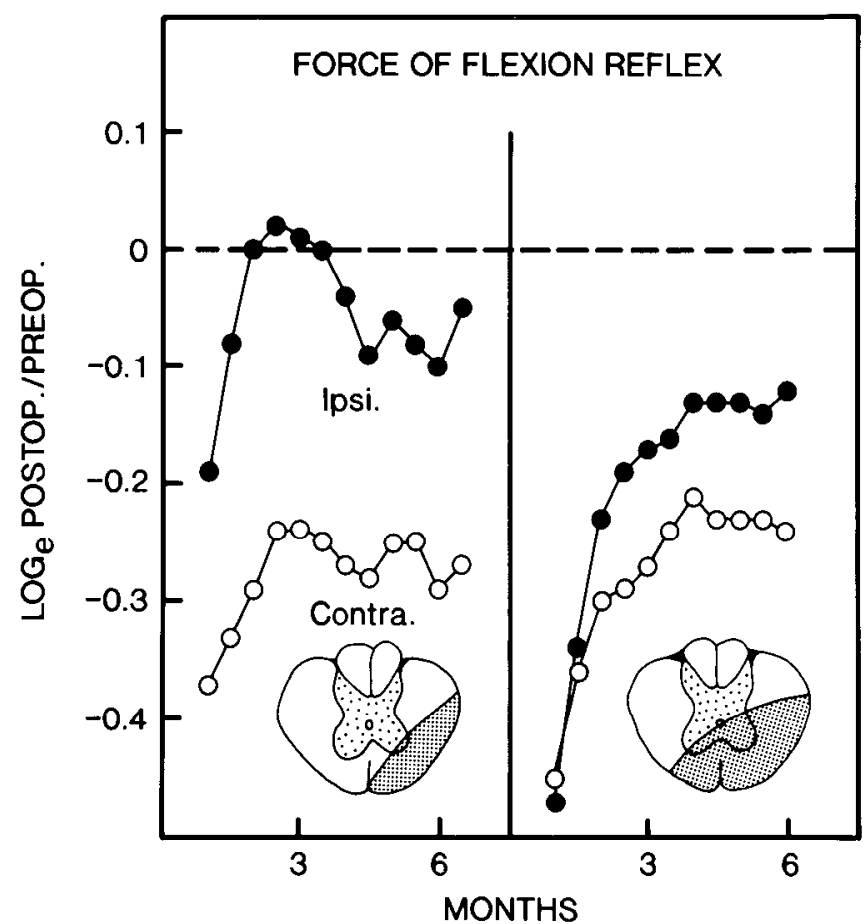

Figure 11. Average log ratios of postoperative/preoperative reflex force over 6 months of postoperative testing for 4 animals with strictly unilateral lesions (left panel; nos. 878, 909, 911, and 877) and 9 animals with lesions that involved the ventral columns bilaterally (right panel. nos. 015, 045, 103, 113, 016, 014, 042, 017, 910). Open symbols, left leg; closed symbols, right leg. Inset, Idealized lesion configurations for animals in the 2 groups.

month, but the deficit in escape performance did not recover in 6 months of testing.

\section{Additional animals}

Figure 12 presents histological reconstructions of lesions in 4 animals not included in the main analysis. The top 2 panels depict lesions which produced effects consistent with the conclusion that superficial interruption of the anterolateral column produces an enduring hypalgesia. The Cebus monkey was involved in a previous study of the effects of secondary lesions on recovered nociceptive reactivity after anterolateral chordotomy (Vierck and Luck, 1979). This animal was not included in that report because recovery from the primary lesion (shown in Fig. 13) did not occur over a 6 month testing period. In contrast, 4 other Cebus monkeys with deeper lesions of the lateral and ventral columns (i.e., extending more medially) recovered nociceptive reactivity within a mean of $43 \mathrm{~d}$ after surgery. Similarly, monkey \#232 in the present series of animals did not give evidence of recovery from hypalgesia contralateral to a superficial lesion. This animal was not included in the main analysis because the postoperative period of testing was short (6 months) relative to the other animals in group $\mathrm{U}$.

The lower 2 reconstructions in Figure 12 represent variations in lesion configuration that precluded inclusion in either group $\mathrm{U}$ or $\mathrm{R}$. The lesion for \#013 involved the lateral and ventral columns bilaterally and included scattered patches of gliosis. As expected, a bilateral deficit of operant reactivity was observed for this animal, comparing postoperative to preoperative performance. Animal \#345 was excluded from the main analysis

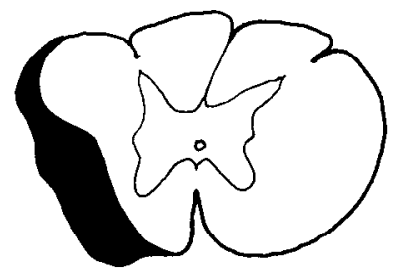

CEBUS
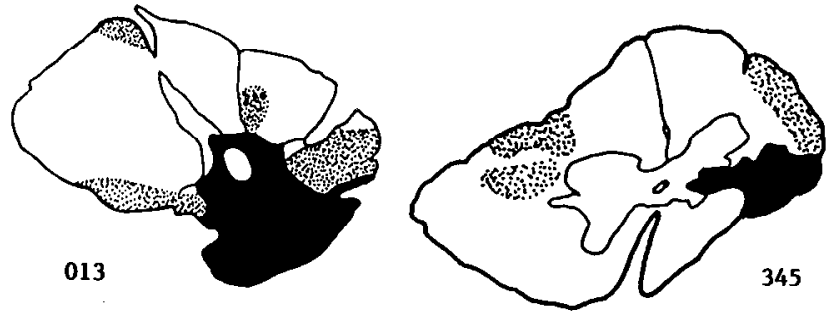

Figure 12. Camera lucida reconstructions of histological sections through the maximal extent of lesions received by 4 animals not included in group $\mathrm{R}$ or $\mathrm{U}$ (see text). Normal tissue is outlined; scar tissue is black; and areas of gliosis are stippled.

because of patches of gliosis in the dorsolateral columns of both sides and because the lesion did not include all of the right anterolateral column. This lesion produced a strictly contralateral hypalgesia that recovered after 8 months of testing.

\section{Discussion}

Acute effects of chordotomy on nociception

Following anterolateral chordotomy in human patients, chronic pain from a contralateral body region is consistently relieved or reduced. Typically, this effect is referred to as analgesia (an absence of pain) in the clinical literature, and this may be the case for chronic pain in the early postoperative period. However, close examination of chordotomy patients' responses to nociceptive stimulation indicates that sensations of phasic pain are reduced, but not eliminated, caudal and contralateral to the lesion (King, 1957; White and Sweet, 1969). Similarly, monkeys exhibit a strictly contralateral reduction of operant reactivity to nociceptive stimulation (hypalgesia) but not to analgesia (Vierck and Luck, 1979; Greenspan et al., 1986). In all cases in the present study, escape thresholds were elevated, and responsivity to suprathreshold levels of stimulation was attenuated. That is, a decrease in nociceptive sensitivity was represented by a parallel rightward shift of the functions relating operant responsivity to stimulus intensity.

The attenuation of operant responsivity was not expressed preferentially on low or high levels of nociception, but it was restricted to response measures related to escape of ES. That is, for 4 animals tested on the combined detection/escape paradigm, detection thresholds were not significantly altered by the spinal lesions (see Greenspan et al., 1986, for details). In contrast, thresholds for escape were more than doubled contralaterally for each of the 18 animals in the present study. Thus, the comparison of detection and escape thresholds served to demonstrate that (1) the animals were not simply responding to the presence of FS on escape trials and (2) the effect of spinal lesions 
on operant responses was selective for nociceptive stimulation of the contralateral leg.

It should be recognized that this or any pain assessment procedure only reveals reactions to a limited portion of the entire spectrum of pain experiences. For example, the monkeys on the escape paradigm respond predominantly (if not exclusively) to nociceptive sensations that are elicited by activity among small myelinated (A delta) peripheral afferents. For human subjects, this "first pain" sensation is dominant with the electrocutaneous stimulation parameters used in the present study (Cooper et al., 1986). Also, escape responses by the monkeys usually occur prior to "second pain" sensations that result from activation of unmyelinated afferents by strong stimuli (Cooper et al., 1986). It is not surprising that reactions to first pain sensations appropriately model the clinical effects of anterolateral chordotomy because spinal neurons that provide spinothalamic tract axons respond to input from both myelinated and unmyelinated nociceptors (e.g., Foreman et al., 1975; Chung et al., 1979).

\section{Chronic effects of chordotomy on nociception}

Numerous follow-up observations of patients have shown that both chronic and acute pain sensations can increase in magnitude (with decreases in threshold) over months to years after anterolateral chordotomy (e.g., Nathan, 1963). For both humans and monkeys, this recovery of nociception occurs for some (approximately $50 \%$ ) but not all cases that have been tested repeatedly. Thus, the operant escape behavior of the monkeys models the responses of human pain patients to spinothalamic tractotomy in terms of both early and long-term effects of the lesions. An important advantage of the present model is that daily testing of the animals reveals the time course of recovery when it occurs. Consistent with reports of human chordotomy, the recovery is delayed in onset (by an average of 3 months for the monkeys) and progresses at varying rates (reaching completion at an average of 7 months for the monkeys).

Some return of nociception following chordotomy might be associated with recovery from edema or from spinal "shock." However, an early change in sensitivity (within the first week) was not evaluated, and the early plateau period of months indicates that these are not important factors in the recovery process described here. Recovery of nociceptive responses could also result from anatomical reorganization (e.g., axonal sprouting) that would reestablish connections to neurons that have been deafferented by the chordotomy. Because spinothalamic projections in primates are convergent to some extent with spinal-lemniscal projections (e.g., in nucleus ventralis posterolateralis; Berkley, 1980; Ma et al., 1987), a framework for somatotopically appropriate synaptic replenishment exists, and this could begin within days of the surgery (Murray and Goldberger, 1986). Several early components of recovery do occur within the first postoperative week and month following spinallemniscal lesions (Vierck et al., 1987); these are revealed by improved accuracy of gross motor movements. However, the later onset of changes in operant responsivity following chordotomy indicates either that axonal sprouting is not a major factor in recovery of nociception or that anatomical reorganization progresses very slowly to the point of influencing nociception.

In the case of lesions of the dorsal column-lemniscal system, a process of late recovery is evident also (Vierck, 1982). A very gradual reacquisition of sensory acuity and fine motor control can occur over months of training and is dependent upon taskspecific practice. It is possible that recovery of nociception is comparable to the practice-dependent reorganization following dorsal column lesions; i.e., the animals in the present study were exposed daily to nociceptive stimulation. Also, human patients may receive a "retraining" of pain systems as a result of chronic bombardment from nociceptors. This possibility is not strongly supported by the present demonstration of recovery of nociception, which differed in several respects from the relearning of lemniscal capacities: (1) When recovery occurs following complete interruption of the dorsal columns, it is seen for all the animals tested, but anterolateral chordotomies of comparable extent can produce variable results. (2) Improvements in sensory or motor capacities following lemniscal lesions are restricted to the impaired limb despite equal amounts of postoperative training of the contralateral limb. In contrast, when nociception increased following chordotomy, it was heightened bilaterally (see Figs. 5, 7).

The ipsilateral increase in nociception for group $\mathrm{R}$ might be related to dysesthetic or paresthetic conditions that have been reported to occur in some instances following spinal cord injury. For example, some chordotomy patients note the presence of new chronic pain or unusual sensations in dermatomes caudal and ipsilateral to the lesion (e.g., Taren et al., 1969; White and Sweet, 1969). When the presence of bilateral peripheral pathology could be ruled out, this effect has been interpreted as a reference of pain sensations (allochiria) from the source of contralateral pain to the side ipsilateral to a chordotomy (Ray and Wolff, 1945; Nathan, 1956; Nagaro et al., 1987; Bowsher, 1988). Thus, enhancement of reactivity to ipsilateral stimulation could result from an additive effect of input from the pathological source of pain at the mirror (contralateral) location on the body. However, simultaneous bilateral stimuli were not presented to the monkeys. In addition, the reference of sensation from the hypalgesic to the ipsilateral side appears in the early postoperative period for human patients (Nathan, 1956; Nagaro et al., 1987; Bowsher, 1988), but ipsilateral hyperesthesia in the present study was late in onset and could develop gradually over months of testing.

Another source of evidence for induction of dysesthesias by spinal lesions has come from reports of self-mutilation (autotomy) of the distal portion of a limb by some monkeys following anterolateral chordotomy (Levitt and Levitt, 1981; Levitt, 1985). The autotomy occurs contralateral to the lesion, and dysesthesias often occur in humans on the side opposite an anterolateral chordotomy (e.g., White, 1963; Pagni, 1976). However, the development of a lateralized dysesthesia does not correspond to the bilateral increase in nociception that was observed in the present study. Also, when skin lesions appeared on the contralateral leg of the monkeys, they were not restricted to animals in group $\mathrm{R}$, and they were not correlated in time with recovery of escape behavior when it occurred. Thus, the presence of skin lesions was not indicative of a process that was fundamental to recovery of nociceptive responses. Overall, the monkeys did not guard or attend to either hindlimb in a consistent manner, suggesting that anterolateral chordotomies do not produce chronic dysesthesias for this species (see also Levitt and Levitt, 1981).

The clinical reports of ipsilateral and/or contralateral alterations of pain sensations for some patients after chordotomy suggest that some pathway(s) supporting (or reinforcing) residual pain sensations receives bilateral input from nociceptive affer- 
ents. Also, the contralateral recovery of nociception for group $\mathrm{R}$ was accompanied by a significant ipsilateral increase in sensitivity for 4 of these 7 animals, and the transient recovery for group $U$ was observed bilaterally. These results suggest that interruption of the spinothalamic tract might "release" pathways with bilateral input to contribute abnormally to pain sensations. This possibility was raised by Wycis and Spiegel (1962), who observed dysesthesias following surgical interruption of the spinothalamic tract at the mesencephalon, and subsequent reports have noted a correlation of dysesthesias with deficits of pain and temperature sensations (Beric et al., 1988; Boivie et al., 1989). That is, following interruption at the thalamus, brain stem, or spinal cord of a pathway that is important for pain and temperature sensations (presumably the spinothalamic tract), some patients develop dysesthesias.

Evidence against the notion that dysesthesias result specifically from releasing influences of the spinothalamic tract on more diffuse pathways (e.g., the spinoreticulothalamic system) is provided by the fact that dysesthesias can be a complication of complete spinal transection in humans (Melzack and Loeser, 1978; Ienz et al., 1987; Beric et al., 1988; Cohen et al., 1988; Rose et al., 1988). Similarly, Levitt (1989) has shown that autotomy can be retained after spinal transection in monkeys. In the present study, recovery from hypalgesia was not attributable to a preferential involvement of the spinothalamic tract and sparing of multisynaptic conduction systems. Given a predominantly superficial distribution of spinothalamic axons in the spinal white matter (Smith, 1957; Lippman and Kerr, 1972; Applebaum et al., 1975; Apkarian and Hodge, 1989b), a chordotomy that is restricted to the perimeter of the lateral and ventral columns should maximally interrupt long ascending pathways and less completely involve medially extensive multisynaptic pathways. However, the superficial lesions in the present study produced contralateral hypalgesias that did not recover.

In a thorough review of reported cases of dysesthesia, Pagni (1976) concluded that the responsible lesion involves the spinothalamic tract and multisynaptic systems of conduction. That is, certain combinations of deafferentation (of specific projection systems) and partial involvement of diffuse projection systems produce hyperalgesia and/or central pain, which can be associated with abnormal bursting patterns of spontaneous and driven activity (Lenz et al., 1987). In this respect, it may be significant that recovery from contralateral hypalgesia and development of ipsilateral hyperalgesia depended upon medially extensive lesions in the present study. Possibly these lesions provided the potential for development of enhanced sensitivity by involving the multisynaptic propriospinal pathways that surround the spinal gray matter (Tower et al., 1941; Nathan and Smith, 1959).

A mechanism for recovery of pain sensitivity that is consistent with bilateral "recovery" from a unilateral deficit is chance occurrence of irritative sequelae to some lesions, generating abnormal activity in bilaterally conducting multisynaptic pathways. This does not predicate that recovery of pain sensitivity and development of dysesthesias are necessarily linked. Rather, it is suggested that tonic or phasic activity in nociceptive pathways can be enhanced by activity in multisynaptic pathways. This hypothesis is compatible with theoretical assertions that the significance of nonspecific somatosensory projection systems for pain sensitivity involves modulation (e.g., amplification) of activity in specific projection systems (Perl, 1984; Vierck et al.,
1986) rather than direct mediation of diffuse sensations or motivational or emotional states.

Additional tests of the effects of spinal lesions of different lateromedial extent could provide important information concerning surgical procedures for reliably and permanently producing hypalgesia for chronic pain patients. The present study indicates that an effective procedure is to interrupt the spinothalamic tract superficially. Similarly, in one of a few investigations of human chordotomy that has included histological verification of the lesions, Nathan and Smith (1979) have presented a series of cases with small anterolateral lesions that produced longlasting hypalgesia.

The present investigation did not directly address the question of which spinal pathway(s) must be present to support nociception after anterolateral chordotomy. However, useful information is provided by variations in lesion extent. First, with regard to the diminished nociception that was present for all animals in the early postoperative period, comparisons of animals with minimal involvement of either ventral column (nos. $909,911,877$, and 232) versus unilateral or bilateral interruption of the ventral columns did not reveal clear differences. In particular, the largest lesions did not produce analgesia. This indicates that ventral spinothalamic pathways (Kerr, 1975) are not critical for nociception that is retained after section of 1 anterolateral column. However, other reports have implicated the ventral columns by demonstrations that (1) pain sensitivity is retained following bilateral anterolateral chordotomies (French et al., 1966; Nathan and Smith, 1966; White and Sweet, 1969) and (2) interruption of both anterolateral and ventral columns of Cebus monkeys produces analgesia, i.e., eliminates operant escape responses (Vierck and Luck, 1979). Thus, residual nociception following a contralateral lesion of the anterolateral column appears to be supported by spinothalamic and spinoreticular pathways in the ventral columns (Kerr, 1975) and the ipsilateral anterolateral column (Kerr and Lippman, 1974; Wall and Noordenbos, 1977; Kevetter et al., 1982; Nahin et al., 1986). That is, sparing of the ventral columns or the ipsilateral lateral column appears to provide a substrate for some pain sensitivity following interruption of the contralateral spinothalamic tract.

In terms of the early sparing of some nociception for all animals, and a progressive increase in sensitivity for some monkeys, recent descriptions of a dorsolateral spinothalamic tract must also be considered. Crossed spinothalamic axons that originate from cells in lamina I of the dorsal horn have been shown iv occupy the dorsolateral column of squirrel monkeys, but these axons do not form a completely separate dorsolateral pathway in Macaque monkeys (Apkarian and Hodge, 1989b). Apkarian and Hodge's material suggests that spinothalamic axons from contralateral lamina I cells are dorsally shifted in the lateral column of Macaques (relative to most of the axons from deeper laminae), but they are not located in the most dorsal tip of the lateral column. Some of these spinothalamic axons could have been spared by lesions in this investigation, contributing to residual nociception after chordotomy.

Relating the dorsolateral extent of individual lesions in the present study to the recovery of operant responses does not implicate dorsolateral sparing. All the lesions extended above the position of the dentate ligament, and some (nos. 017,013) spared only a small dorsolateral portion of the lateral column. Several lesions of animals in group $\mathrm{R}$ were among the most dorsal in extent (nos. 910, 017), and the superficial lesions in group U spared most of the dorsolateral column (nos. 909, 877, 
911). It is possible that individual differences in location of spinothalamic axons account for recovery by some animals from anterolateral chordotomy, and experiments to test this possibility are underway. However, a previous investigation of Cebus monkeys demonstrated that recovered nociceptive reactivity was retained following secondary interruption of the dorsolateral column (by lateral hemisection on the side of a previous anterolateral lesion). This finding indicates that dorsolateral axons are not crucial for recovery from hypalgesia after chordotomy.

\section{Comparison of the effects of chordotomy on operant and reflexive reactions}

In addition to a severance of ascending axons, an anterolateral spinal lesion interrupts descending pathways (e.g., Dahlstrom and Fuxe, 1965; Kneisley et al., 1978) that modulate the excitability of neurons within the dorsal, intermediate, and ventral gray of caudal segments (Westlund and Coulter, 1980; Carlton et al., 1985; Basbaum et al., 1986). These serotonergic and noradrencrgic systems have been shown to produce primarily inhibitory effects on dorsal horn neurons (Willis, 1982; Yaksh, 1985; Mokha et al., 1986; Jones and Gebhart, 1987), and interruption of inhibitory influences on somatosensory input is expected to produce both hyperesthesia and hyperreflexia. Operating under this assumption - that sensory input to projection neurons and segmental reflex circuits would be modulated alikemany investigations have utilized reflexive responses to evaluate influences on nociception by descending systems. However, to test for a correspondence of reflex and sensory effects, it is important to compare measures of each in response to manipulations of the descending systems. For interruption of descending influences by an anterolateral spinal lesion, this comparison is most appropriate for stimulation of the ipsilateral side that is supplied by intact lemniscal and spinothalamic pathways.

In contrast to the predominance of inhibition on dorsal horn neurons, facilitatory effects on ventral horn neurons and on spinal reflexes can be produced by serotonergic or noradrenergic agonists (Fung and Barnes, 1981; Carp and Rymer, 1986; Wiesenfeld-Hallin, 1987; Suzuki et al., 1988). Other descending systems that may project via the anterolateral columns can inhibit activation of motoneurons (e.g., Jankowska et al., 1968). Thus, anterolateral lesions could produce either hyperreflexia or hyporeflexia, depending on the relative potency of different influences on the dorsal and ventral horns (White and Neuman, 1983).

In the present study, it was clear that the early ipsilateral effect of the lesions was to decrease the amplitudes of flexion responses to the same stimuli that elicited normal sensory (operant) reactions on that side. Apparently, interruption of facilitatory actions on the intermediate and ventral horns has a greater impact on reflex responsivity than interruption of inhibitory influences on the dorsal horn. Also, the absence of an ipsilateral effect on operant responses in the early postoperative period suggests that the descending anterolateral systems exert ipsilateral influences predominantly upon autonomic and somatic reflex responsivity. Thus, operant reactions and segmental reflexes were not affected alike by the chordotomy.

The finding that the force of flexion reflexes was attenuated caudal to anterolateral chordotomy has implications for models of spasticity that can result from spinal cord injury. Clinically, spasticity is characterized by exaggeration of stretch reflexes and of flexion reflexes (e.g., Lance, 1980; Shahani and Young, 1980). Laboratory animal models of spasticity from spinal cord injury have typically employed lateral hemisection to induce an ipsilateral hyperreflexia (e.g., Teasdale et al., 1958; Murray and Goldberger, 1974; Noki et al., 1976; Hultborn and Malmsten, 1983). However, neither behavioral nor electrophysiological evidence of spasticity has been consistently observed for segments caudal to a lateral hemisection at thoracic levels in cats (Hultborn and Malmsten, 1983; Ashby and McCrea, 1987; R. L. Carter and L. A. Ritz, unpublished observations) or monkeys (Meltzer et al., 1963). Also, the results of the present study demonstrate that interruption of the anterolateral and/or ventral column produces the opposite effect (hyporeflexia). Thus, as indicated by the flexion reflex, complete lateral hemisection at a thoracic level is not an optimal spinal lesion for modeling spasticity.

Another finding that has relevance to models of spasticity is that reflex force was decreased bilaterally following unilateral lesions. Often, spasticity for experimental preparations has been defined on the basis of lateral asymmetry, assuming that greater ipsilateral reflex strength is referenced to normal contralateral responsivity. However, strictly unilateral interruption of an anterolateral column produced greater contralateral hyporeflexia than was observed for the ipsilateral limb. For these animals, the flexion reflex of the ipsilateral limb was depressed relative to preoperative values, but it was considerably more responsive than the contralateral limb. Thus, unilateral interruption of the ventral spinal pathways complicates interpretations of spasticity by producing bilateral effects, and therefore reflex strength for these animals must be related to stabilized preoperative measurements.

The bilateral changes in reflex amplitude appear to be consistent with anatomical and physiological evidence for bilateral terminations of descending modulatory systems (e.g., Martin et al., 1979; Westlund and Coulter, 1980; Hodge et al., 1981; Davies et al., 1983; Jones and Yang, 1985). However, there is little information on the level at which pathways from the brain stem cross to innervate neurons in the contralateral spinal gray matter. Indirect evidence in favor of bilateral spinal terminations of descending axons from one anterolateral column is provided by an anatomical investigation of the animals in this study. Bullitt et al. (1988) demonstrated that the unilateral lesions produced a bilateral shift in distribution of primary afferent terminals in spinal segments caudal to the lesions. That is, relative to intact animals, the percentage of primary afferent terminations within spinal laminae III and IV was increased bilaterally, and the percentage of terminals in the superficial dorsal horn (laminae I and IIo) was decreased on both sides. Thus, bilateral alterations of segmental reflexes and redistributions of afferent terminations were produced in the same animals, and these effects might have resulted from adjustments to partial deafferentation of the gray matter on both sides, caudal to the lesion.

An evaluation of performance following lesions that were strictly unilateral or that involved both ventral columns reveals further differences in effects on operant and reflex responses to nociceptive stimulation. For the measures of operant reactivity, involvement of both ventral columns did not influence the early postoperative deficit contralateral to the anterolateral lesion, and neither the timc course nor the amount of recovery was systematically affected by unilateral versus bilateral involvement of the ventral columns. Furthermore, the ipsilateral effects 
of chordotomy on operant reactions did not differ for animals with unilateral or bilateral lesions.

The ipsilateral hyporeflexia that resulted from anterolateral chordotomy was influenced by inclusion of both ventral columns in the lesion. That is, on the average, a greater degree of ipsilateral hyporeflexia was evident for animals with bilateral interruption of the ventral columns than for animals with unilateral lesions; and the larger lesions produced comparable hyporeflexia for the 2 legs, in contrast to a greater contralateral effect for the ipsilateral lesions. An additive effect of anterolateral and ventral column interruption is consistent with anatomical evidence that some descending projections from the brain stem to the intermediate and ventral gray are located in the ventral column (Basbaum et al., 1978). In particular, direct projections to the ventral horns (e.g., from nucleus raphe obscurus) are conveyed via the ventral columns (Dahlstrom and Fuxe, 1965; Martin et al., 1978). Other brain-stem regions (e.g., raphe pallidus, locus coeruleus, and related reticular nuclei) project down the anterolateral and ventral columns to facilitate reflex circuits in the intermediate and ventral horns (Holstege et al., 1979; Westlund and Coulter, 1980; Chan et al., 1986). More information is needed, however, on the laterality of terminations from one ventral column.

The recovery of nociception that can occur following spinothalamic chordotomy might reflect processes of reorganization at spinal or supraspinal sites (or both). For example, interruption of descending pathways of influence on spared projection neurons could result in a variety of consequences, including an increase in afferent driving of these neurons by nociceptive afferents (Murray and Goldberger, 1974; Sedevic et al., 1983) and a decrease of inhibitory modulation (Willis et al., 1977; Mokha et al., 1986; Jones and Gebhart, 1987). Similarly, partial deafferentation of thalamic neurons by interruption of spinothalamic axons could result in enhanced activation of nocircceptive neurons by other pathways that normally contribute convergent inputs (Berkley, 1980; Ma et al., 1987). Evidence for spinal reorganization as the critical factor would have been provided if patterns of recovery were identical for the reflex and operant measures of nociceptive reactivity. For example, changes in reactivity over months of testing were generally bilateral for the operant and reflexive responses, suggesting that a common factor contributed to reorganization of segmental and ascending systems of nociceptive processing. However, a direct correspondence of the time course of operant and reflexive recovery was not observed. In general, reflex recovery was gradual, consistent, and monotonic, but the operant reactions were more labile, showing reversals of recovery in some animals. Eightyfive percent of the animals recovered significantly from an initial hyporeflexia, but only $47 \%$ showed prolonged and significant enhancement of operant reactivity after chordotomy. These different patterns of recovery indicate that the underlying mechanisms were not identical. Either the projection neurons and segmental circuits were strongly influenced by different processes of reorganization at the spinal cord, or supraspinal plasticity was a major factor in determining the recovery of nociception.

\section{References}

Aoki M, Mori S, Fujimori B (1976) Exaggeration of knee-jerk following spinal hemisection in monkeys. Brain Res 107:471-485.

Apkarian AV, Hodge CJ (1989a) The primate spinothalamic path- ways: I. A quantitative study of the cells of origin of the spinothalamic pathway. J Comp Neurol 288:447-473.

Apkarian AV, Hodge CJ (1989b) The primate spinothalamic pathways: II. The cells of origin of the dorsolateral and ventral spinothalamic pathways. J Comp Neurol 288:474-492.

Applebaum AE, Beall JE, Foreman JE, Willis WD (1975) Organization and receptive fields of primate spinothalamic tract neurons. J Neurophysiol 38:572-586.

Ashby P, McCrea DA (1987) Ncurophysiology of spinal spasticity. In: Handbook of the spinal cord, vol 4: congenital disorders and trauma (Davidoff RA, ed), pp 119-143. New York: Marcel Dekker.

Basbaum AI, Clanton CH, Fields HL (1978) Three bulbospinal pathways from the rostral medulla of the cat: an autoradiographic study of pain modulating systems. J Comp Neurol 187:209-224.

Basbaum AI, Ralston DD, Ralston HJ III (1986) Bulbospinal projections in the primate: a light and electron microscopic study of a pain modulating system. J Comp Neurol 250:311-323.

Beric A, Dimitrijevic MR, Lindblom U (1988) Central dysesthesia syndrome in spinal cord injury patients. Pain 34:109-116.

Berkley KJ (1980) Spatial relationships between the terminations of somatic sensory and motor pathways in the rostral brainstem of cats and monkeys. I. Ascending somatic sensory inputs to lateral diencephalon. J Comp Neurol 193:283-317.

Boivie J (1979) An anatomical reinvestigation of the termination of the spinothalamic tract in the monkey. J Comp Neurol 186:343-369.

Boivie J, Leijon G, Johansson I (1989) Central post-stroke pain-a study of the mechanisms through analyses of the sensory abnormalities. Pain 37:173-185.

Bowsher D (1957) Termination of the central pain pathway in man: the conscious appreciation of pain. Brain 80:606-622.

Bowsher D (1988) Contralateral mirror-image pain following anterolateral chordotomy. Pain 88:63-65.

Bullitt E, Stofer WD, Vierck CJ, Perl ER (1988) Reorganization of primary afferent nerve terminals in the spinal dorsal horn of the primate caudal to anterolateral chordotomy. J Comp Neurol 270: 549-558.

Carlton SM, Chung JM, Leonard RB, Willis WD (1985) Funicular trajectories of brainstem neurons projecting to the lumbar spinal cord in the monkey (Macaca fascicularis). J Comp Neurol 241:382-404.

Carp JS, Rymer WZ (1986) Enhancement by serotonin of tonic vibration and stretch reflexes in the decerebrate cat. Exp Brain Res 62: $111-122$.

Chan JYH, Fung SJ, Chan SHH, Barnes CD (1986) Facilitation of lumbar monosynaptic reflexes by locus coeruleus in the rat. Brain Res 369:103-109.

Chung JM, Kenshalo DR Jr, Gerhart KD, Willis WD (1979) Excitation of primate spinothalamic neurons by cutaneous C-fiber volleys. J Neurophysiol 42:1354-1369.

Cohen MJ, McArthur DL, Volpe M, Schandler SL, Gerber KE (1988) Comparing chronic pain from spinal cord injury to chronic pain of other origins. Pain 35:57-63.

Cooper BY, Vierck CJ Jr (1986) Measurement of pain and morphine hypalgesia in monkeys. Pain 26:361-392.

Cooper BY, Vierck CJ Jr, Yeomans DC (1986) Selective reduction of second pain sensations by systemic morphine in humans. Pain 24 : 93-116.

Dahlstrom A, Fuxe K (1965) Evidence for the existence of monoamine neurons in the central nervous system. II. Experimentally induced changes in the intraneuronal amine levels of bulbospinal neuron systems. Acta Physiol Scand (Suppl 247) 64:6-36.

Davies JE, Marsden CA, Roberts MHT (1983) Hyperalgesia and the reduction of monoamines resulting from lesions of the dorsolateral funiculus. Brain Res 261:59-68.

Foreman RD, Applebaum AE, Beall JE, Trevino DL, Willis WD (1975) Responscs of primate spinothalamic tract neurons to electrical stimulation of hindlimb peripheral nerves. J Neurophysiol 38:132-145.

French LA, Chou SN, Story JL (1966) Cervical tractotomy: technique and clinical usefulness. In: Pain (Knighton RS, Dumke PR, eds), pp 311-320. Boston: Little, Brown.

Fung SJ, Barnes CD (1981) Evidence of facilitatory coerulospinal action in lumbar motoneurons of cats. Brain Res 216:299-311.

Giesler GJ, Spiel HR, Willis WD (1981) Organization of spinothalamic tract axons within the rat spinal cord. J Comp Neurol 195:243252.

Greenspan JD, Vierck CJ Jr, Ritz LA (1986) Sensitivity to painful 
and non-painful electrocutaneous stimuli in monkeys: effects of anterolateral chordotomy. J Neurosci 6:380-390.

Greenspan JD, Vierck CJ Jr, Ritz LA, Cohen RH (1987) Long-term changes in purposive and reflexive responses to painful stimulation in monkeys following anterolateral chordotomy. Pain (Suppl) 4:402.

Hodge CJ, Apkarian AW, Stevens R, Vogilsang G, Wisnicki HJ (1981) Locus coeruleus modulation of dorsal horn unit responses to cutaneous stimulation. Brain Res 204:415-420.

Holstege G, Kuypers HGJM, Boer RC (1979) Anatomical evidence for direct brain stem projections to the somatic motoneuronal cell groups and autonomic preganglionic cell groups in cat spinal cord. Brain Res 171:329-333.

Hultborn H, Malmsten J (1983) Changes in segmental reflexes following chronic spinal cord hemisection in the cat. 1. Increased monosynaptic and polysynaptic ventral root discharges. Acta Physiol Scand 119:405-422.

Jankowska E, Lund S, Lundberg A, Pompeiano O (1968) Inhibitory effects evoked through ventral reticulospinal pathways. Arch Ital Biol 106:124-140.

Joncs BE, Yang T-Z (1985) The cfferent projections from the reticular formation and the locus coeruleus studied by anterograde and retrograde axonal transport in rat. J Comp Neurol 242:56-92.

Jones SL, Gebhart GF (1987) Spinal pathways mediating tonic, coeruleospinal, and raphe-spinal descending inhibition in the rat. J Neurophysiol 58:138-159.

Kahn EA, Rand RW (1952) On the anatomy of anterolateral cordotomy. J Neurosurg 9:611-619.

Kemplay SK, Webster KE (1986) A qualitative and quantitative analysis of the distributions of cells in the spinal cord and spinomedullary junction projecting to the thalamus of the rat. Neuroscience 17:769789.

Kerr FWL (1975) The ventral spinothalamic tract and other ascending systems of the ventral funiculus of the spinal cord. J Comp Neurol 159:335-357.

Kerr FWL, Lippman HH (1974) The primate spinothalamic tract as demonstrated by anterolateral cordotomy and commissural myelotomy. Adv Neurol 4:147-156.

Kevetter GA, Haber LH, Yezierski RP, Chung JM, Martin RF, Willis WW (1982) Cells of origin of the spinoreticular tract in the monkey. J Comp Neurol 207:61-74.

King RB (1957) Postchordotomy studies of pain threshold. Neurol (Minneap) 7:610-614.

Kneisley LW, Biber MP, LaVail JH (1978) A study of the origin of brain stem projections to monkey spinal cord using the retrograde transport method. Exp Neurol 60:116-139.

Kuhn RA (1953) Organization of tactile dermatomes in cat and monkey. J Neurophysiol 16:169-182.

Kuru M (1949) Sensory paths in the spinal cord and brain stem of man. Tokyo: Sogensya.

Lance JW (1980) Symposium synopsis. In: Spasticity: disordered motor control (Feldman RG, Young RR, Koella WP, eds), pp 485-494. Chicago: Year Book.

Lenz FA, Tasker RR, Dostrovsky JO, Kwan HC, Gorecki J, Hirayama T, Murphy JT (1987) Abnormal single-unit activity recorded in the somatosensory thalamus of a quadriplegic patient with central pain. Pain 31:225-236.

Levitt M (1985) Dysesthesias and self-mutilation in humans and subhumans: a review of clinical and experimental studies. Brain Res Rev 10:247-290.

Levitt M (1989) Postcordotomy spontaneous dysesthesias in macaques: recurrence after spinal cord transection. Brain Res 481:4756.

Levitt M, Levitt J (1981) The deafferentation syndrome in monkeys: dysesthesias of spinal origin. Pain 10:129-147.

Lippman HH, Kerr FWL (1972) Light and electron microscopic study of crossed ascending pathways in the anterolateral funiculus in monkey. Brain Res 40:496-499.

Ma W, Peschanski M, Ralston HJ III (1987) The differential synaptic organization of the spinal and lemniscal projections to the ventrobasal complex of the rat thalamus. Evidence for convergence of the two systems upon single thalamic neurons. Neuroscience 22:925-934.

Martin GF, Humbertson AO, Laxson LS, Panneton WM, Tschismadia I (1979) Spinal projections from mesencephalic and pontine reticular formation in North American opossum: a study using axonal transport techniques. J Comp Neurol 187:373-400.
Martin RF, Jordan LM, Willis WD (1978) Differential projections of cat medullary raphe neurons demonstrated by retrograde labelling following spinal cord lesions. J Comp Neurol 182:77-88.

Mehler WR, Feferman ME, Nauta WJH (1960) Ascending axon degeneration following anterolateral cordotomy. An experimental study in the monkey. Brain 83:718-750.

Melzack R, Loeser JD (1978) Phantom body pain in paraplegics: evidence for a central "pattern generating mechanism" for pain. Pain 4:195-210.

Meltzer GE, Hunt RS, Landau WM (1963) Fusimotor function. Part III. The spastic monkey. Arch Neurol 9:133-136.

Mokha SS, McMillan JA, Iggo A (1986) Pathways mediating descending control of spinal nociceptive transmission from the nuclei locus coeruleus (LC) and raphe magnus (NRM) in the cat. Exp Brain Res 61:597-606.

Murray M, Goldberger ME (1974) Restitution of function and collateral sprouting in cat spinal cord: the partially hemisected animal. J Comp Neurol 158:19-36.

Murray M, Goldberger ME (1986) Replacement of synaptic terminals in lamina II and Clarke's nuclcus after unilateral lumbosacral dorsal rhizotomy in adult cats. J Neurosci 6:3205-3217.

Nagaro T, Kimura S, Arai T (1987) A mechanism of new pain following cordotomy; reference of sensation. Pain 30:89-91.

Nahin RL, Madsen AM, Giesler GJ Jr (1986) Funicular location of the ascending axons of neurons adjacent to the spinal cord central canal in the rat. Brain Res 384:367-372.

Nathan PW (1956) Reference of sensation at the spinal level. J Neurol Neurosurg Psychiatry 19:88-100.

Nathan PW (1963) Results of antero-lateral cordotomy for pain in cancer. J Neurol Neurosurg Psychiatry 26:353-362.

Nathan PW, Smith MC (1959) Fasciculi proprii of the spinal cord in man. Brain 82:610-668.

Nathan PW, Smith MC (1966) Some tracts of the anterior and lateral columns of the spinal cord. In: Pain (Knighton RS, Dumke PR, eds), pp 47-57. Boston: Little, Brown.

Nathan PW, Smith MC (1979) Clinico-anatomical correlation in anterolateral cordotomy. Adv Pain Res Ther 3:921-926.

Pagni CA (1976) Central pain and painful anesthesia. Prog Neurol Surg 8:132-257.

Perl ER (1984) Why are selectively responsive and multireceptive neurons both present in somatosensory pathways? In: Somatosensory mechanisms (von Euler C, Franzen O, Lindblom U, Ottoson D, eds), pp 141-162. London: MacMillan Press.

Ray BS, Wolff HG (1945) Studies on pain. "Spread of pain"; evidence on site of spread within the neuraxis of effects of painful stimulation Arch Neurol Psychiatr 53:257-261.

Rose M, Robinson JE, Ells P, Cole JD (1988) Pain following spinal cord injury: results from a postal survey. Pain 34:101-102.

Sedevic MJ, Ovelmen-Levitt J, Karp R, Mendell LM (1983) Increase in nociceptive input to spinocervical tract neurons following chronic partial deafferentation. J Neurosci 3:1511-1519.

Shahani BT, Young RR (1980) The flexor reflex in spasticity. In: Spasticity: disordered motor control (Feldman RG, Young RR, Koella WP, eds), pp 287-295. Chicago: Year Book.

Smith MC (1957) Observations on the topography of the lateral column of the human cervical spinal cord. Brain 80:263-272.

Spiller WG, Martin E (1912) The treatment of persistent pain of organic origin in the lower part of the body by division of the anterolateral column of the spinal cord. JAMA 58:1489-1490.

Suzuki T, Ono H, Fukuda H (1988) Different effects of norepinephrine and serotonin on the electrical toe stimulation-induced reflexes in the rat spinal cord. Gen Pharmacol 19:373-375.

Taren JA, Davis R, Crosby EC (1969) Target physiologic corroboration in stereotaxic cervical cordotomy. J Neurosurg 30:569-584.

Teasdale, RD, Magladery JW, Ramey EH (1958) Changes in reflex patterns following spinal cord hemisection in cats. Johns Hopkins Med J 103:223-235.

Tower S, Bodian D, Howe H (1941) Isolation of intrinsic and motor mechanisms of the monkey's spinal cord. J Neurophysiol 4:388-397.

Vierck CJ Jr (1982) Plasticity of somatic sensations and motor capabilities following lesions of the dorsal spinal columns in monkeys. In: Changing concepts of the nervous system (Morrison AR, Strick PL, eds), pp 151-169. New York: Academic.

Vierck CJ Jr, Cooper BY (1984) Guidelines for assessing pain reactions and pain modulation in laboratory animal subjects. In: Advances in 
pain research and therapy (Kruger L, Liebeskind JC, eds), pp 305322. New York: Raven.

Vierck CJ Jr, Luck MM (1979) Loss and recovery of reactivity to noxious stimuli in monkeys with primary spinothalamic cordotomies, followed by secondary and tertiary lesions of other cord sectors. Brain 102:233-248.

Vierck CJ Jr, Hamilton DM, Thornby JI (1971) Pain reactivity of monkeys after lesions to the dorsal and lateral columns of the spinal cord. Exp Brain Res 13:140-158.

Vierck CJ Jr, Cooper BY, Cohen RH (1983a) Human and non-human primates' reactions to painful electrocutaneous stimuli and to morphine. In: Animal pain perception and alleviation (Kitchell RL, Erickson $\mathrm{HH}$, eds), pp 117-132. Bethesda, MD: American Physiological Society.

Vierck CJ Jr, Cooper BY, Franzen O, Ritz LA, Greenspan JD (1983b) Behavioral analysis of CNS pathways and transmitter systems involved in conduction and inhibition of pain sensations and reactions in primates. In: Progress in psychobiology and physiological psychology (Sprague J, Epstein A, eds), pp 113-165. New York: Academic.

Vierck CJ Jr, Greenspan JD, Ritz LA, Yeomans DC (1986) The spinal pathways contributing to the ascending conduction and the descending modulation of pain scnsations and reactions. In: Spinal afferent processing (Yaksh TL, ed), pp 275-329. New York: Plenum.

Vierck CJ Jr, Cooper BY, Leonard CM (1987) Motor capacities and deficiencies after interruption of the dorsal spinal columns in primates. In: Neurology and neurobiology, Vol 30, Effects of injury on somatosensory systems (Pubols L, Sessle B, eds), pp 429-436. New York: Liss.

Walker AE (1940) The spinothalamic tract in man. Arch Neurol Psychiatr 43:284-298.
Wall PD, Noordenbos W (1977) Sensory functions which remain in man after complete transection of dorsal columns. Brain 100:641653.

Westlund KN, Coulter JD (1980) Descending projections of the locus coeruleus and subcoeruleus-medial parabrachial nuclei in monkey: axonal transport studies and dopamine- $\beta$-hydroxylase immunocytochemistry. Brain Res Rev 203:235-265.

White JC (1963) Anterolateral cordotomy-its effectiveness in relieving pain of non-malignant disease. Neurochirurgia 6:83-102.

White JC, Sweet WH (1969) Pain and the neurosurgeon: a forty-year experience. Springfield, IL: C. C Thomas.

White SR, Neuman RS (1983) Pharmacological antagonism of facilitatory but not inhibitory effects of serotonin and norepinephrine on excitability of spinal motoneurons. Neuropharmacology 22:489-494.

Wiesenfeld-Hallin Z (1987) Intrathecal noradrenaline has a dose-dependent inhibitory or facilitatory effect on the flexion reflex in the rat. Acta Physiol Scand 130:507-511.

Willis WD (1982) Control of nociceptive transmission in the spinal cord. Heidelberg: Springer-Verlag.

Willis WD, Haber LH, Martin RF (1977) Inhibition of spinothalamic tract cells and interneurons by brain stem stimulation in the monkey. J Neurophysiol 40:968-981.

Wycis HT, Spiegel EA (1962) Long-range results in the treatment of intractable pain by stereotaxic midbrain surgery. J Neurosurg 19:101107.

Yaksh TL (1985) Pharmacology of spinal adrenergic systems which modulate spinal nociceptive processing. Pharmacol Biochem Behav $22: 845-858$. 